University of Redlands

\title{
Hydrological Analysis for Infrastructure Planning and Development at the North Entrance Joshua Tree National Park
}

A Major Individual Project submitted in partial satisfaction of the requirements

for the degree of Master of Science in Geographic Information Systems

by

Erick Makori Nyangari

Mark Kumler, Ph.D., Committee Chair

Ruijin Ma, Ph.D.

Dean Djokic, Ph.D.

August 2020 
Hydrological Analysis for Infrastructure Planning and Development at the North Entrance of Joshua Tree National Park

Copyright (C) 2020

by

Erick Makori Nyangari 

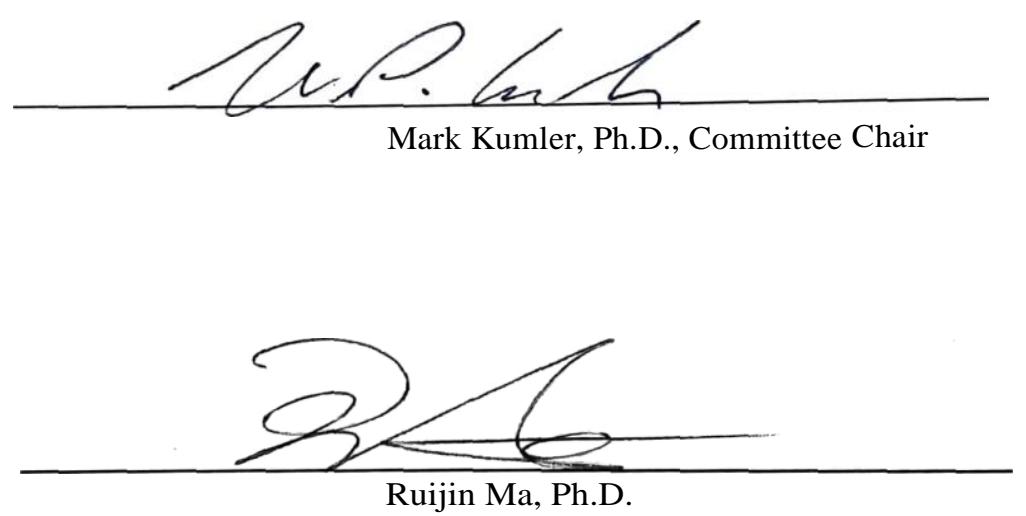

Ruijin Ma, Ph.D.

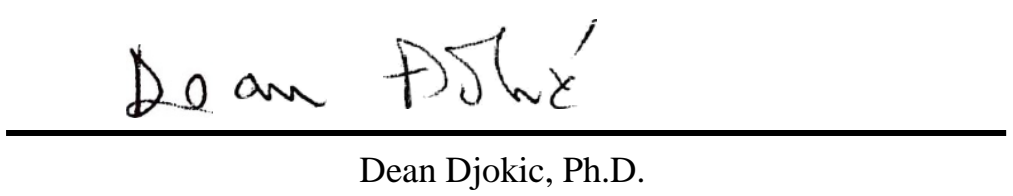

August 2020 



\section{Acknowledgements}

First and foremost, I would like to thank my family for the emotional support they gave me throughout the program and for keeping me in their prayers.

I would also like to express my gratitude to my advisor Professor Mark Kumler for the support and guidance to ensure that I complete my project in time without forgetting Dean Djokic for his guidance and support. Special thanks to MS GIS program faculty members for the support and help offered throughout the program.

I would also like to express my gratitude to Mr. Luke Sabala for giving me the opportunity to undertake this project and providing the required materials and guidance and for regular check on to see if I am running into any problems.

Finally, I would like to thank Jack and Laura Dangermond for sponsoring my graduate studies and making this academic journey possible. 


\begin{abstract}
Hydrological Analysis for Infrastructure Planning and Development at the North Entrance Joshua Tree National Park

by

Erick Makori Nyangari
\end{abstract}

Rains in the Mojave Desert region are intense and result in the destruction of property. This destruction is significant and affects development plans in the area. Joshua Tree National Park (JTNP) is one of the areas affected as a result of flash floods in the Mojave Desert region.

As part of the efforts to minimize the effects caused by flash floods in the park, there was a need to carry out a hydrological analysis of surface runoff in order to map out high risk areas that are susceptible to floods after Monsoonal rains, identify areas in the park that require diversion berms, and establish the effectiveness of the existing diversion berms.

The analysis result was a 3D topographic model and a map that contains high flood risk areas and potential areas where diversion berms may be constructed to divert surface runoff and protect the park's infrastructure. 


\section{Table of Contents}

Chapter 1 - Introduction ................................................................................................. 1

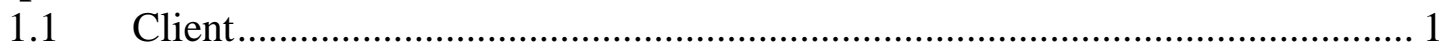

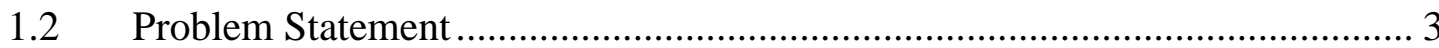

$1.3 \quad$ Proposed Solution ................................................................................. 4

1.3.1 Goals and Objectives ............................................................................... 4

1.3.2 Scope

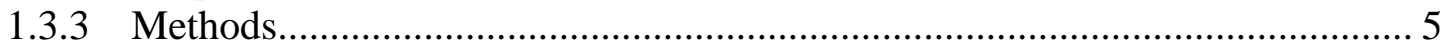

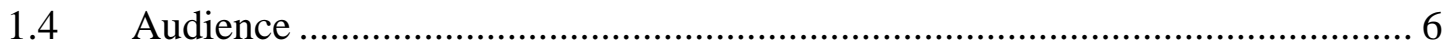

1.5 Overview of the Rest of this Report .......................................................... 6

Chapter 2 - Background and Literature Review ........................................................... 7

$2.1 \quad$ Southwest Monsoonal Rains................................................................. 7

2.2 Surface Runoff from Precipitation........................................................ 9

2.2.1 Rational Formula ............................................................................ 10

2.2.2 NRCS Methodology ............................................................................ 10

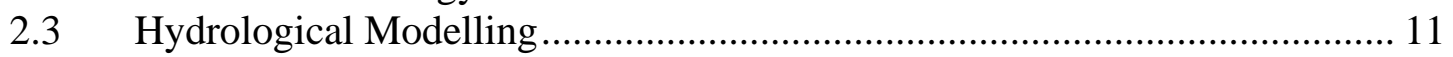

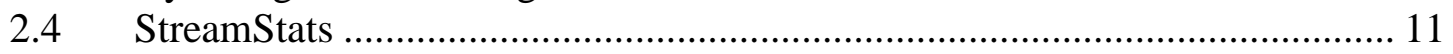

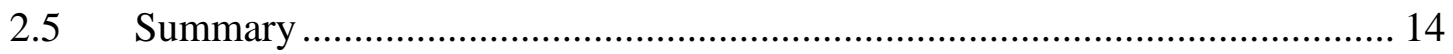

Chapter 3 - Systems Analysis and Design....................................................................... 15

$3.1 \quad$ Problem Statement .............................................................................. 15

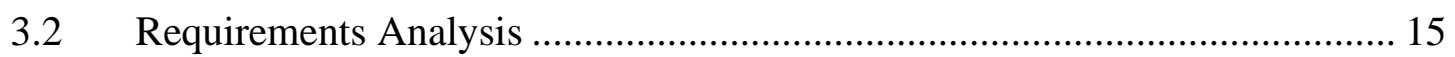

3.2.1 System Design Functional Requirements ..................................................... 16

3.2.2 System Design Non-Functional Requirements ............................................... 16

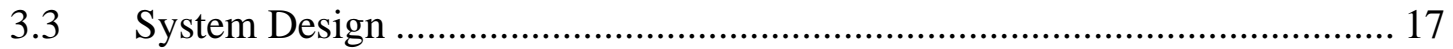

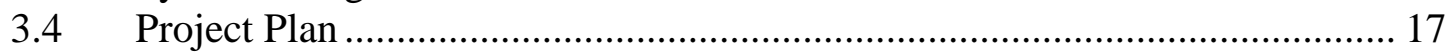

3.4.1 Project Inception ................................................................................... 17

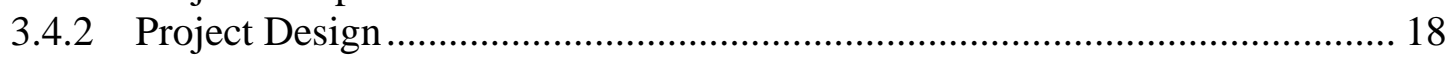

3.4.3 Project Implementation ......................................................................... 18

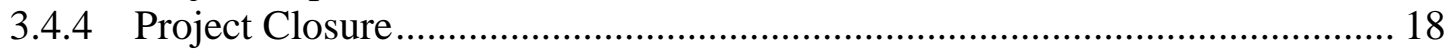

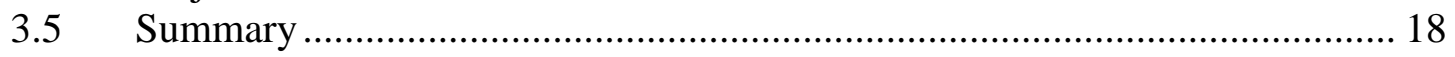

Chapter 4 - Database Design...................................................................................................... 19

4.1 Conceptual Data Model ......................................................................... 19

4.2 Logical Data Model ……………………………............................. 20

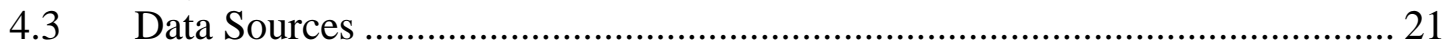

4.4 Data Scrubbing and Loading …………………….................................... 22

4.4.1 Elevation Data Preprocessing ……………………................................. 22

4.4.2 Depressionless DEM Processing ……………………………………….... 22

4.4.3 Terrain Preprocessing …………………………................................... 23

4.4.4 StreamStats Discharge ………………………................................. 24

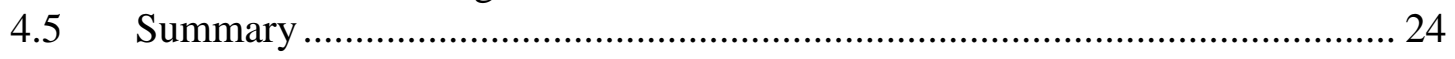

Chapter 5 - Implementation................................................................................................... 25

$5.1 \quad$ Elevation Preprocessing ...................................................................... 25

5.2 Terrain Preprocessing and Delineation.......................................................... 27 


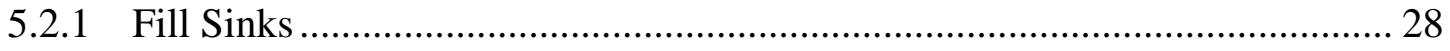

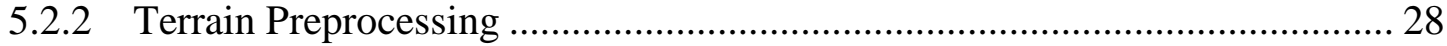

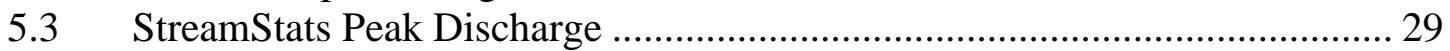

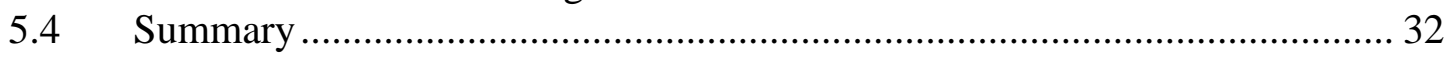

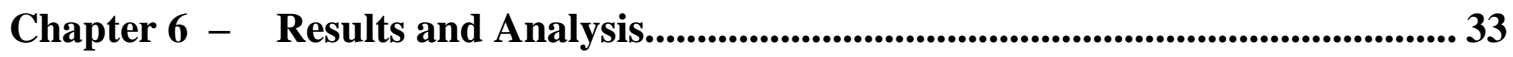

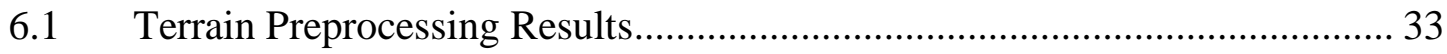

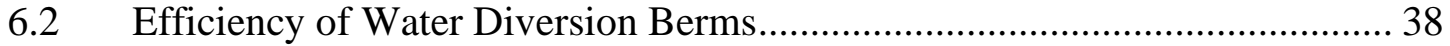

6.3 Areas that Need Additional Water Diversion Berms.................................... 48

Chapter 7 - Conclusions and Future Work .......................................................... 52

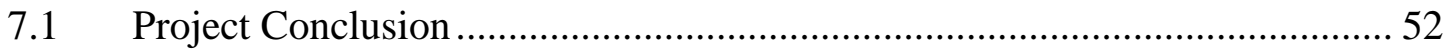

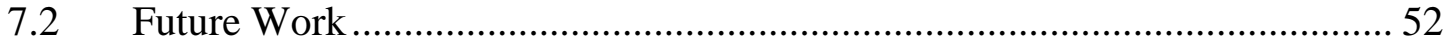

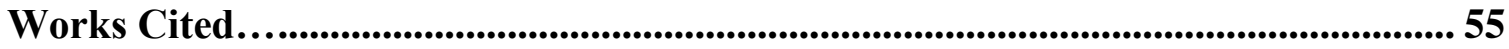

Appendix A. Project Model................................................................................................ 59

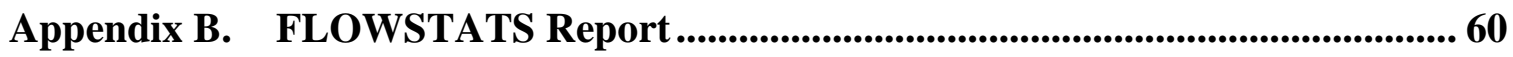




\section{Table of Figures}

Figure 1-1: Joshua Tree National Park, North Entrance......................................... 2

Figure 1-2: The location of North Entrance within Joshua Tree National Park.......... 3

Figure 1-3: Destruction of Utah Trail Road by flood. ........................................... 4

Figure 2-1: An overview map of the Mojave Desert and the study area. .................... 8

Figure 2-2: StreamStats regions for California ...................................................... 13

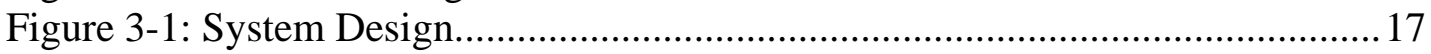

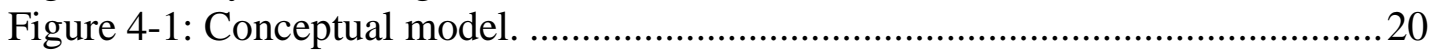

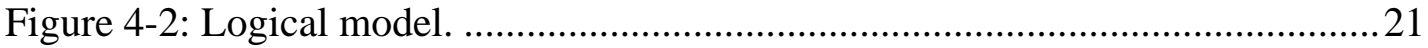

Figure 4-3: Terrain preprocessing model...............................................................23

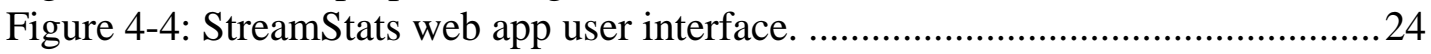

Figure 5-1 : LiDAR point cloud extent for the Northern entrance. ..........................26

Figure 5-2: A 0.2m DEM generated from LiDAR point cloud data...........................27

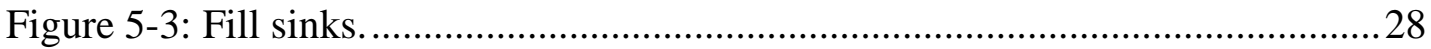

Figure 5-4: Terrain preprocessing workflow. ........................................................29

Figure 5-5: An excerpt from StreamStats report................................................. 30

Figure 5-6: StreamStats batch processing tool user interface................................. 31

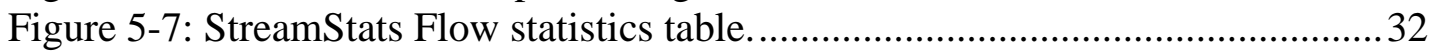

Figure 6-1: Drainage lines and drainage points from a 0.5m DEM............................ 34

Figure 6-2: Drainage lines and drainage points from a $1 \mathrm{~m}$ DEM.............................. 35

Figure 6-3: Drainage lines and drainage points from a 5m DEM............................ 36

Figure 6-4: A figure comparing the output from different resolutions.......................37

Figure 6-5: Noticeable differences from different resolutions at a larger scale ........38

Figure 6-6: Diversion berms, major roads and stream channels..............................39

Figure 6-7: Influence of water diversion berms on a watershed drainage line.......... 40

Figure 6-8: An effective water diversion berm....................................................... 41

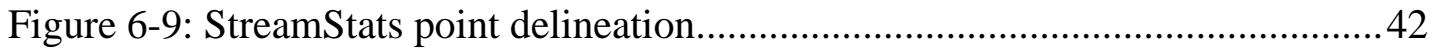

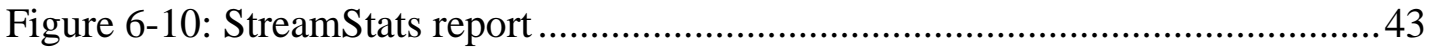

Figure 6-11: Normal depth calculator by NWS ................................................ 44

Figure 6-12: Drainage Area Characterization table ................................................. 45

Figure 6-13: Point precipitation estimate for the area from NOAA Atlas 14...........46

Figure 6-14: Dam capture capacity for different heights based on precipitation ......47

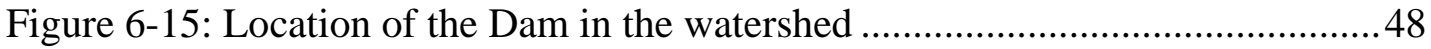

Figure 6-16: A section that needs additional berms................................................49

Figure 6-17: Point delineation for a selected stream without water berms................50

Figure 6-18: Flow statistics from StreamStats ....................................................51 



\section{List of Tables}

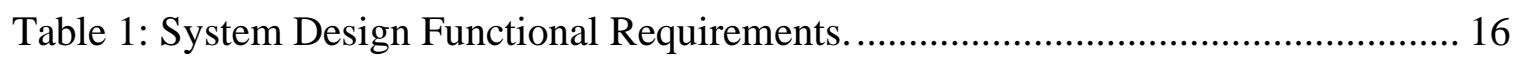

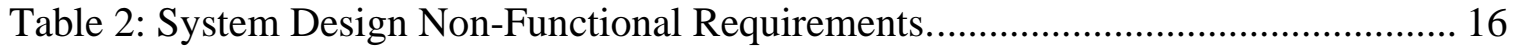

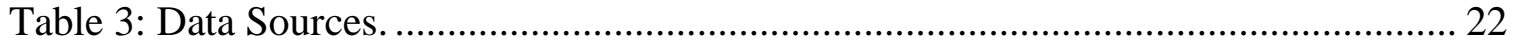





\section{List of Acronyms and Definitions}

$\begin{array}{ll}\text { 3D } & \text { Three-Dimension } \\ \text { CN } & \text { Curve Number } \\ \text { DEM } & \text { Digital Elevation Model } \\ \text { GIS } & \text { Geographic Information System } \\ \text { GDB } & \text { Geodatabase } \\ \text { HEC-HMS } & \text { Hydrologic Engineering Center - Hydrologic Modeling System } \\ \text { HEC-RAS } & \text { Hydrologic Engineering Center - River Analysis System } \\ \text { JTNP } & \text { Joshua Tree National Park } \\ \text { LiDAR } & \text { Light Detection and Ranging } \\ \text { MXD } & \text { ArcMap Document } \\ \text { NAD 83 } & \text { North American Datum 1983 } \\ \text { NPS } & \text { National Park Service } \\ \text { SCE } & \text { Southern California Edison } \\ \text { UTM } & \text { Universal Transverse Mercator }\end{array}$





\section{Chapter 1 - Introduction}

Deserts form part of the world's landscape and support a variety of animal and plant species. Humans derive economic benefits from deserts despite the daily challenges, such as flash floods which ultimately alter the surface of the deserts mostly by soil erosion. Joshua Tree National Park (JTNP) is one such example. The park is located in the greater Mojave Desert, and experiences monsoonal rains that are sparse but intense and usually last a short time. This heavy rain within a short period of time leads to flash floods in the park which consequently leads to destruction of park amenities such as local roads and other buildings.

The primary purpose of this project was to model the surface water runoff in the park and map out areas that are vulnerable to flash floods and propose locations where water diversion berms can be erected to protect road and other structures that are at risk.

\subsection{Client}

The client for this project was Joshua Tree National Park (JTNP). Mr. Luke Sabala, Physical Sciences Branch Chief at JTNP, served as the main point of contact and provided data on the park's roads, existing water diversion berms, digital elevation model (DEM), and LiDAR datasets. The client's goal was to mitigate the effects caused on roads especially the Utah Trail road and buildings such as Sky's the Limit Observatory and Nature Center, which are regularly damaged by the floods during rainy seasons in the park. 


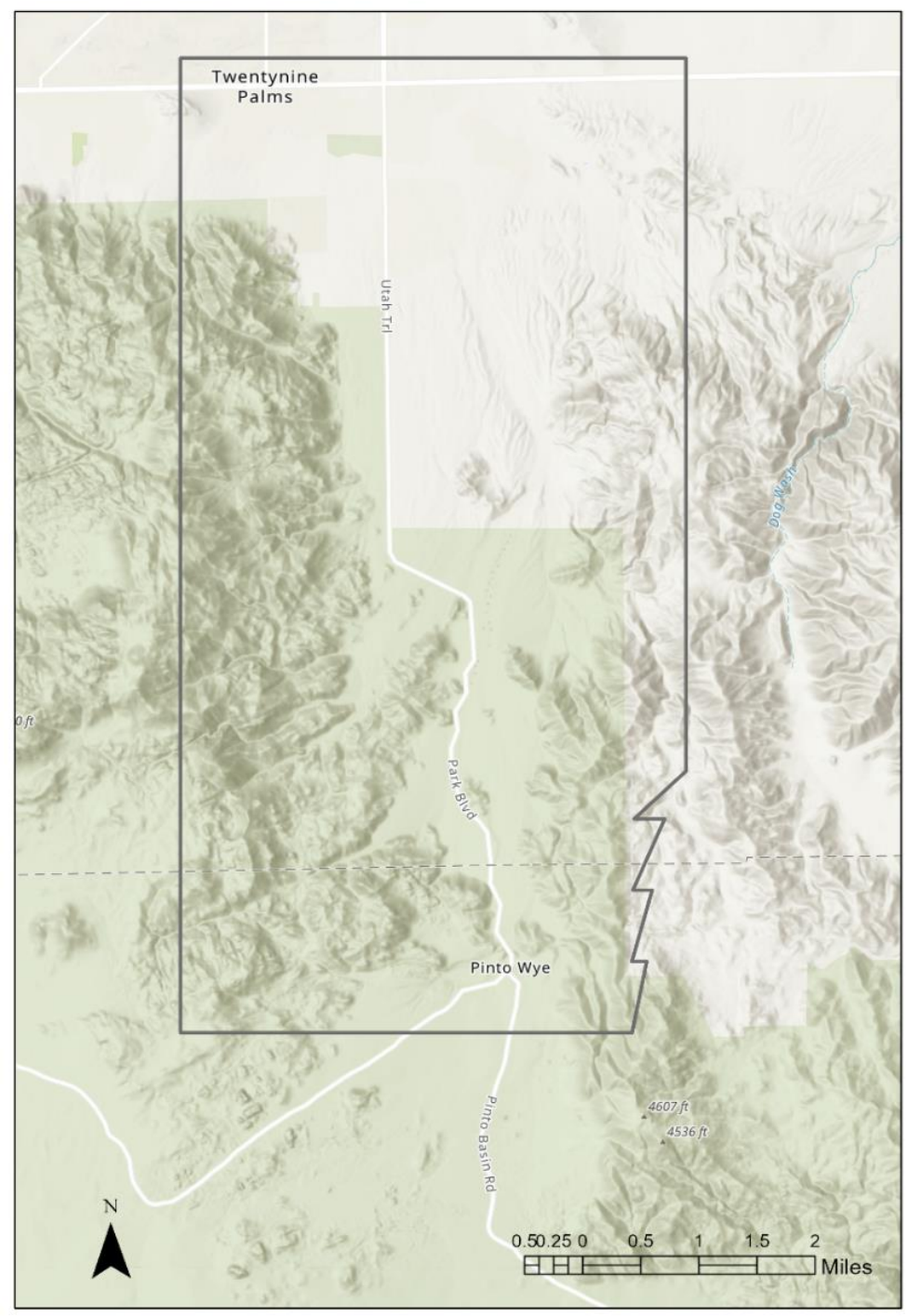

Figure 1-1: Joshua Tree National Park, North Entrance. 


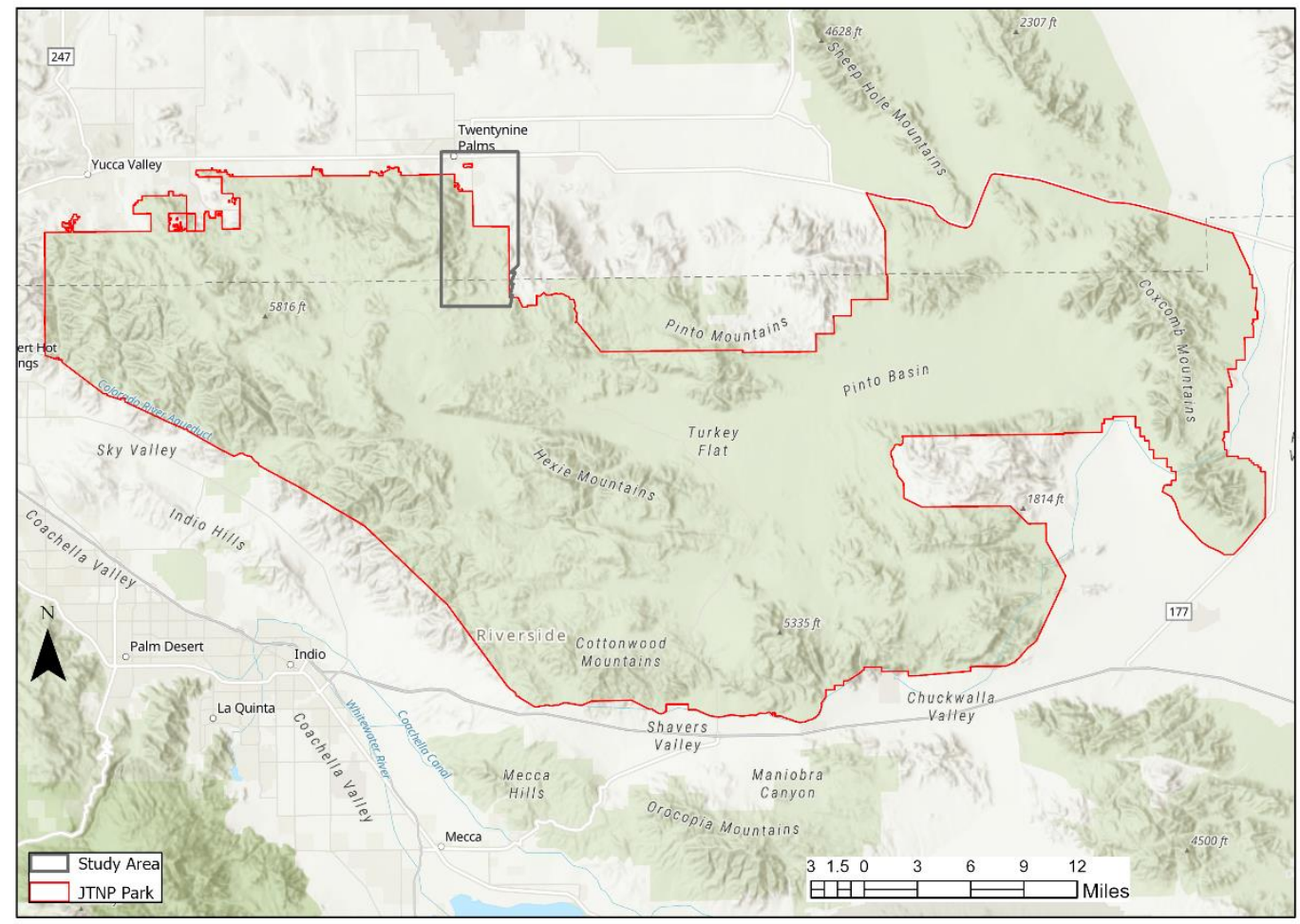

Figure 1-2: The location of North Entrance within Joshua Tree National Park.

\subsection{Problem Statement}

The client, JTNP, wanted to protect infrastructures around the North Entrance of the park from the impacts of flash floods. Additionally, the client wanted to determine the effectiveness of water diversion berms. The park is prone to flash floods each year and this presents a significant challenge especially when developing structures that support the operations of the park, including power line cables coming into the park. 


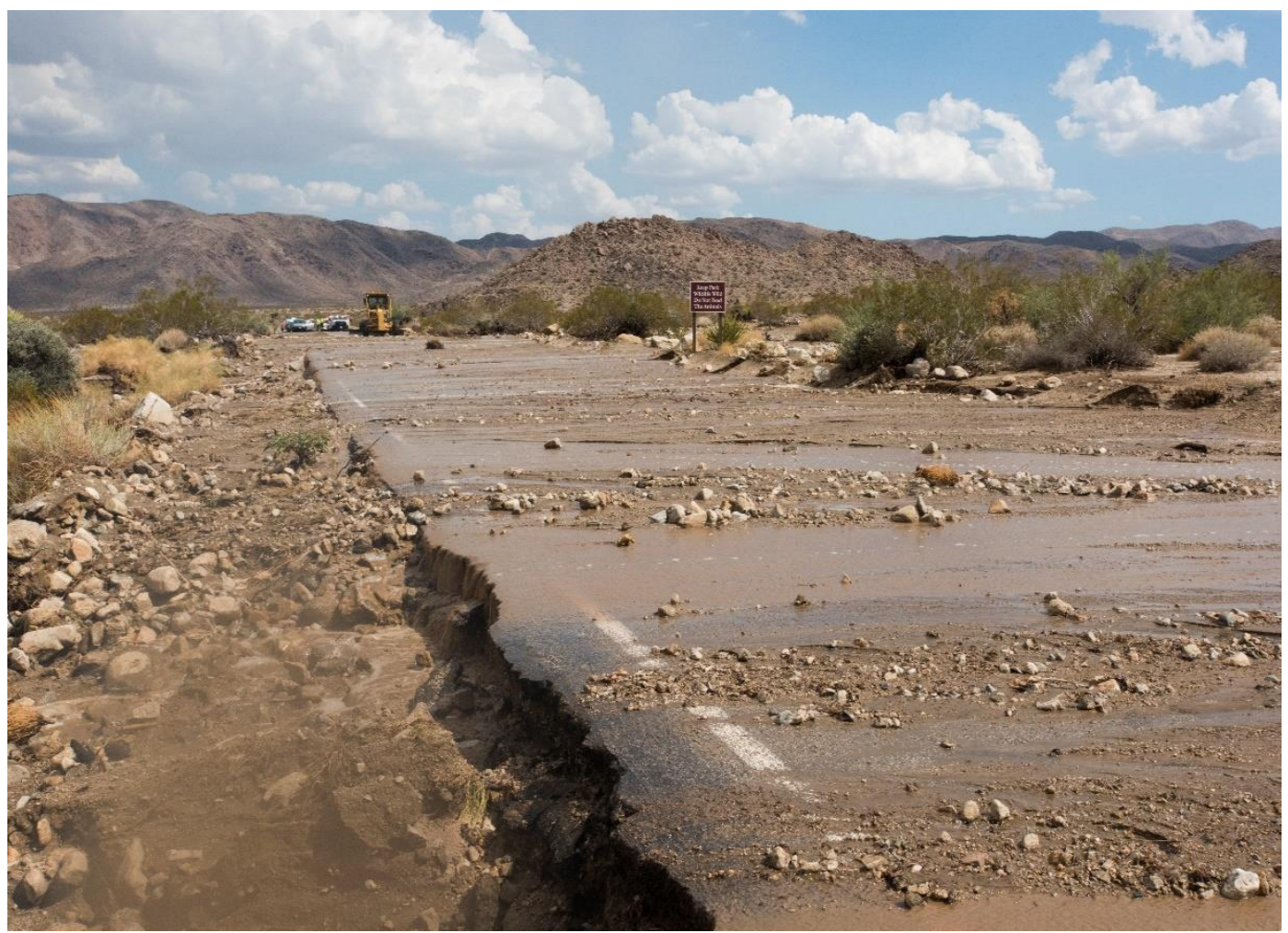

Figure 1-3: Destruction of Utah Trail Road by flood.

Photo: https://www.flickr.com/photos/joshuatreenp/20309475054/in/photostream/

\subsection{Proposed Solution}

The proposed solution involved the use of ESRI Arc Hydro 10.6 tools to model surface water runoff in the area around the park. A 3D topographic model was best suited to represent the water flow direction and general terrain of the park. The topographic model was derived from a digital elevation model (DEM).

Stream discharge volume from StreamStats by USGS which uses a set of regression analysis to estimate flow volume (discharge) in a stream, was used to provide flow volume in the streams and channels that flow through the park during the rainy season. The topographic model will incorporate existing water diversion berms, drainage lines, local roads, and stream discharge from StreamStats.

\subsubsection{Goals and Objectives}

The primary goal of this project was to produce a flood risk map and predictive models within the park where water conveyance features will be most effective, thereby minimizing the effects often associated with flash floods after monsoonal rains. The purpose of this project was to build a topographic model for JTNP North Entrance in a database using Geographic Information System (GIS) and identify high risk areas within the park that need additional water diversion berms to protect them from adverse flash floods impacts. The resulting flood risk map will be a stand-alone product and the 3Dtopographic model will be contained in a database. 
The objectives for this project were attained using:

- Topographic modelling using ESRI Arc Hydro tools, watershed delineation tools and raster tools to create a DEM for the area.

- Using StreamStats drainage discharge form USGS to estimate the flow volume in the drainage channels that cross the Utah Trail Road in the Park.

The flood risk map and the 3D topographic model in a geodatabase will be of great help to the park managers in making development decision.

\subsubsection{Scope}

The study area of this project was North Entrance, JTNP within the larger Mojave Desert Region. The deliverables for this project included a set of two maps and one 3D topographic model in a geodatabase. In order to achieve these requirements, the datasets were clipped to cover the area of interest.

Although there were other independent hydrological analysis tools such as Groundwater (GW) toolbox developed by U.S. Geological Survey (USGS), this project used ArcGIS Arc Hydro toolset to derive runoff characteristics across the surface of the North Entrance. The client provided the required datasets including LiDAR, recently mapped historic and modern water conveyance features, water drainage layers, infrastructure and DEMs for the area. A digital surface model (DSM) for the area was not considered because of data limitations.

This project was limited to modelling surface water flow along the streams and channels and excluded underground water flow as a result of infiltration, even though this has an effect on the amount of water available for surface runoff after a monsoonal event.

\subsubsection{Methods}

In order to achieve the objectives of this project, the project was split into phases. These phases were data cleaning and preparation, data analysis, and construction of a 3D topographic model.

Data provided by the client for this project were LiDAR datasets, diversion berms, local roads, buildings, park facilities. The first step in data cleaning and preparation was crucial so as to have an accurate model and eliminate data inaccuracies as well as ensuring that there were no data gaps in the input data. Additionally, this was to ensure that only the required data was being loaded into a geodatabase to cut down on the amount of time it takes to process data, especially the LiDAR data. This step also included clipping the datasets to only cover the study area and projected to World Geodetic System Datum 1984 (WGS84), Universal Transverse Mercator Zone 11 North (UTM Zone 11N).

The second task was to calculate the stream discharge for the streams that cross the Utah Trail road in JTNP, and this was made possible by using StreamStats web app by USGS. The resulting stream discharge in the streams was the key to understanding the amount of water that flows in the channels. Because the water diversion berms in the park are repaired once every 5 years, StreamStats discharge peak discharge for a 5-year period was used. 
ArcGIS desktop 10.6 and Arc Hydro 10.6 tools were used to delineate the watershed and generate streamlines that flow through the northern entrance of the park. To complete the 3D topographic model, stream discharge from StreamStats was incorporated. Suitability analysis was carried out to identify potential areas where new water conveyance features will need to be constructed. The output constituted a predictive model showing areas that are prone to flooding and marking them out. A second map was generated to show areas that needed to be reinforced to protect existing infrastructure.

\subsection{Audience}

The primary audience for this project includes: NPS park management, 29 Palms City managers, SCE planners, and adjacent private property owners around the North Entrance of the park. A secondary audience for this project includes GIS personnel who are interested in using StreamStats discharge for topographic modelling using Arc Hydro tools to solve flash floods problems.

\subsection{Overview of the Rest of this Report}

This rest of this report consists of chapters two to seven. Chapter two will discuss issues related to flash floods and present a literature review to help in understanding the underlying problem. Additionally, Chapter two will also present existing flash flood modeling techniques. Chapter three will outline system requirements and design and all elements in the used in the analysis. Chapter five will discuss database design used. Chapters six and seven will discuss project results, final products from this project and further research that can be done in the use of GIS in flash flood control. 


\section{Chapter 2 - Background and Literature Review}

The purpose of this project was to analyze the effectiveness of the existing water diversion berms in Joshua Tree National Park (JTNP) north entrance and identify areas where new ones may be built in order to protect the park's existing infrastructure from destruction caused by flash floods. In order to achieve this project's objectives, it was important to examine surface runoff methodologies that have been used in the past. To properly carry out a hydrological analysis required for this project, a review of past work in hydrological analysis and modelling tools was necessary.

\subsection{Southwest Monsoonal Rains}

This section discusses the Monsoon season in the North American continent, focusing on the Mojave Desert Region where the area of interest for this project is located. JTNP is considered a desert because it receives little precipitation and has little vegetation cover. The Mojave Desert is located in the North American continent and mostly experiences rainfall during winter that result in precipitation either as rainfall or snow. The Southwest monsoon covers the northwestern parts of Mexico and parts of the U.S., specifically the Southwest region where the Mojave Desert region is located (Lennox, 2007). 


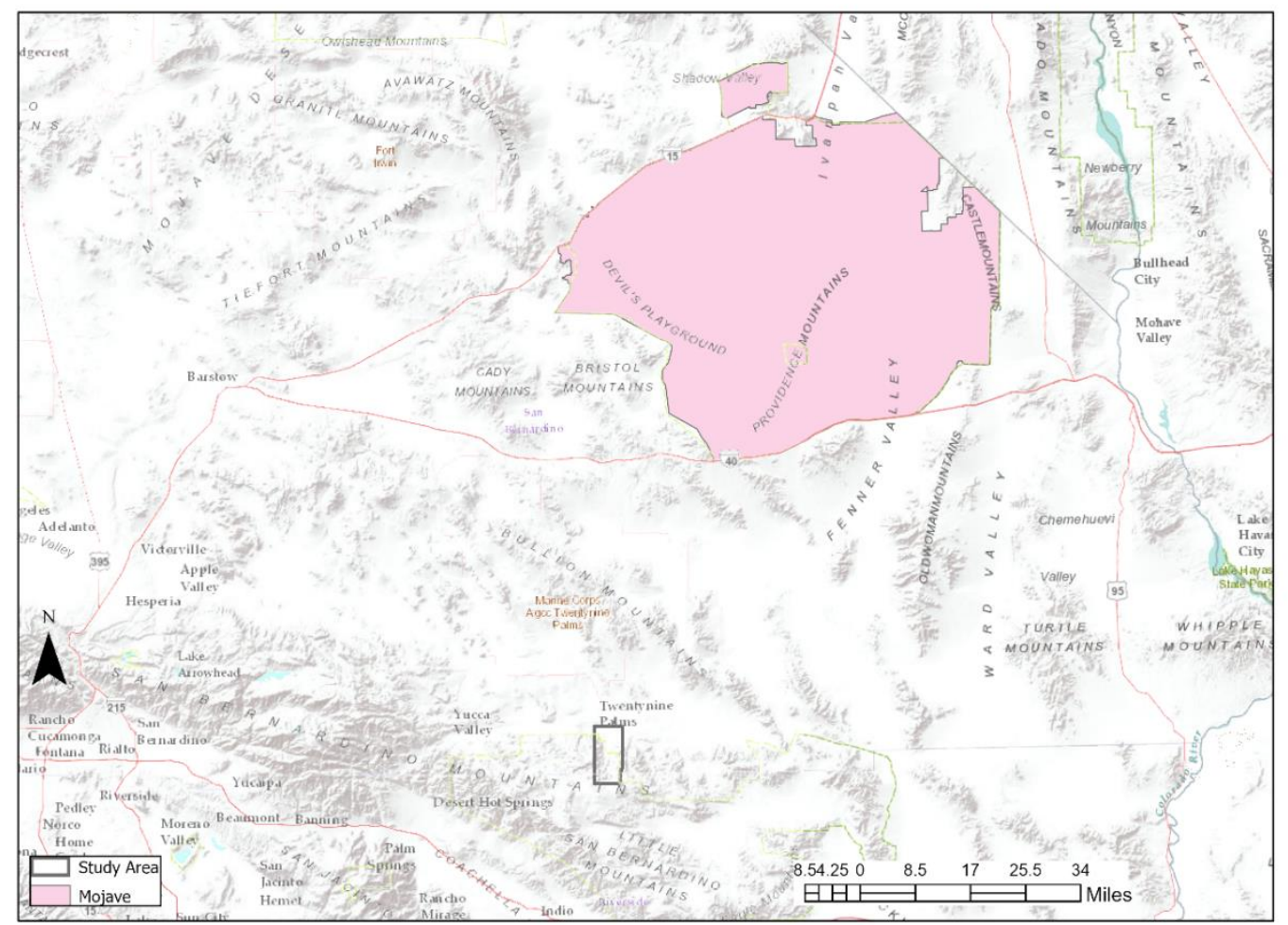

Figure 2-1: An overview map of the Mojave Desert and the study area.

During the cold Monsoon season that lasts between November and March, the southwest regions in the U.S experience heavy precipitation in the form of rainfall while the mountainous areas receive precipitation in the form of snow. The Mojave Desert Region receives most of its annual precipitation during the winter season and is thus considered a cold desert. Additionally, the region generally experiences coldest temperatures during this time. The little precipitation has been attributed to the fact that the desert is on the leeward side of both the Sierra Nevada and the Transverse Ranges, as noted by Mooney and Zavaleta (2016).

The absence of vegetation cover in most deserts pose several challenges, and of interest to this project, is flash floods. During this time, there is intense precipitation within a short period of time, and coupled with bare surfaces that lack ground cover, the infiltration rate is low while surface runoff is high.

The Mojave River is a critical drainage system in the Mojave Desert during the rainy season. The river is found in the San Bernardino mountains in San Bernardino County, downstream from where both the Deep Creek and West Fork Mojave rivers converge to form the Mojave River, which then flows into the Soda Dry Lake (Lines, 1996). As a result, the downstream of the Mojave River overflows during the wet Monsoon season because of high precipitation in the mountain areas and convergence of the two tributaries which make up the Mojave River. The size of Deep Creek basin near Hesperia is about $134 \mathrm{mi}^{2}$ while that of West Fork Mojave River near Hesperia is about $70.3 \mathrm{mi}^{2}$ 
(Mullen et al., 1993 ) which makes the Mojave River prone to floods during the rainy seasons especially for the areas downstream.

Historical records indicate that the Mojave Desert has had the wettest and the driest years which coincide with El Nino and La Nina weather patterns. The hottest areas in the Mojave Desert Regions are found in Death Valley and the driest known years were 1929 and 1953 (Walker \& Landau 2018, p. 264). The coldest areas in the Mojave Desert Region, which also receive snow during the cold season according to Walker and Landau (2018), are found around Mount Charleston in Nevada.

\subsection{Surface Runoff from Precipitation}

To understand the hydrological modelling task required for this project, it was important to review direct runoff, runoff process, and factors that affect it. The area of interest for this project is the JTNP north entrance which is located in Twentynine Palms city within the Mojave Desert Region.

The highest point in the Mojave Desert Region is about 4,000 feet while the lowest point is near Badwater Basin at about 280 feet below sea level (Bowers, 1999).

According to Lisk and Fox (2005), the Mojave Desert Region gets most of its water by precipitation during the wet Monsoon season, although the mountain peaks and mountain areas in the region receive snow during the same period (Chambers \& Lapthorn, 2008). The large difference in elevation between low lying areas such as Badwater Basin and the high mountain peaks makes the region unique in the sense that both rain and snow are experienced in the region during the wet monsoon season (Walker \& Landau, 2018).

During a storm, water falling on the ground surface either gets absorbed by the soil or, if the soil is saturated because of high rainfall intensity falling within a short period of time, most of it will flow as surface runoff along the surface into streams that drain the watershed of an area (Angulo-Jaramillo et al., 2016). According to Deodhar (2008), several factors influence the infiltration rates in soils. Some of these factors include: the slope of the surface, rainfall intensity, and absence or presence of vegetation cover in the area. These factors therefore need to be considered when determining and calculating surface runoff and infiltration rates in an area.

Several methods have been used to estimate runoff in attempt to design efficient storm sewers. One challenge that is encountered in calculating surface runoff is how to accurately achieve this since some generalization is made for the entire surface under study. The most widely used methods in hydrology are purely based on rainfall intensity that the area receives (Walesh, 1991), even though precipitation intensity received in the same area may not be uniform during a storm. The most widely used methods to estimate runoff are the Rational Method and the Natural Resource Conservation Service (NRCS) methodology.

Subsection 2.2.1 will discuss some of the methods used to estimate surface runoff that are based on rainfall intensity. 


\subsubsection{Rational Formula}

The Rational Formula method according to Tung and Mays (2002) was a widespread formula that was used in designing drainage systems in the nineteenth century. Using the Rational Formula, the runoff can be derived by:

$$
\mathrm{Q}=\mathrm{C} i \mathrm{~A}
$$

Where: $\mathrm{Q}=$ runoff in cubic feet per second

$\mathrm{C}=$ runoff coefficient

$i=$ rainfall intensity in inches per hour

$\mathrm{A}=$ size of the drainage basin in acres

As shown in equation (1), the rainfall intensity, runoff coefficient and the area of the drainage basin are the main factors that are considered in the Rational Formula. One of the limitations as noted by Akan (1993) is that the application of the Rational Formula is limited to an urban drainage area and small watersheds. Additionally, the rational method is based on some assumptions that could potentially make the method inaccurate in calculating surface runoff. One of the assumptions made is that the rainfall intensity is constant throughout the storm and this may not be true (Akan, 1993). As a result, this method may not be applicable in a large water basin or in rural areas.

\subsubsection{NRCS Methodology}

The United States Department of Agriculture Natural Resource Conservation Service Curve Number (USDA-NRCS-CN) is a method developed by the USDA to measure overland flow based on soil characteristics such as soil type and soil group. The Curve Number $(\mathrm{CN})$ surface runoff is a common runoff estimation method because of its simplicity in its application (Mishra \& Singh, 2011). According to Mishra and Singh (2011), the $\mathrm{CN}$ for any given soil group can be calculated using the following equation.

$$
Q=\frac{(P-I a)^{2}}{(P-I a)+S}
$$

Where:

$\mathrm{Q}=\operatorname{runoff}(\mathrm{in})$

$\mathrm{P}=$ rainfall (in)

$\mathrm{S}=$ potential maximum retention after runoff begins (in)

Ia $=$ initial abstraction (in)

The CN method by USDA is a suitable method to calculate overland flow based on soil factors like land usage and soil moisture content (Eyelade, 2012). The CN is represented in a table with soils classified into four hydrologic soil groups namely: A, B, C and D. The common criteria used by the $\mathrm{CN}$ method in classifying the soil types into the four groups is by land use (Mays, 2019). Since the $\mathrm{CN}$ is contained in a table for each soil group and type, to compute the surface runoff of a drainage area, it is important to establish the soil group and characteristics of the area of interest beforehand.

Despite the ease of use and simplicity of $\mathrm{CN}$ in calculating runoff, the duration of storm is not taken in consideration and this is evident in the equation as there is no time element. This makes the method less accurate in estimating runoff. 


\subsection{Hydrological Modelling}

Throughout the world, flooding has led to destruction of buildings and other important infrastructures. For example, the Mississippi River floods in 1993 caused massive damage to roads and other structures (Parola et al., 1998). Seward (2017) estimates that floods in the US caused damages worth $\$ 260$ billion between 1980 and 2013. Other effects resulting from floods include loss of lives, destruction of livelihoods, and several thousands of people left homeless.

Hydrological modelling has thus gained popularity in an effort to minimize the damages caused and lives lost due to floods. With the advent of computers and advancement in technology, flood simulations can now be done within a computer environment. An example of hydraulic modelling software available include HEC-RAS that is made and maintained by the Hydrological Engineering Center of the U.S Army Corps of Engineers and widely used in flood modelling. Another precipitation runoff modelling software is Hydrologic Modeling System (HEC-HMS) that uses precipitation to model runoff (Maskey, 2004).

Hydrological modelling in Geographic Information Systems (GIS) can be done using Arc Hydro which needs spatial elevation data for the area. The elevation data can be either a digital elevation model (DEM) or a triangulated irregular network (TIN). Elevation data and spatial data used in GIS modelling generally have a large size and this may negatively impact the time taken to process such datasets. Maidment and Djokic (2000) however suggest that DEMs are orderly and easy to process when modelling in GIS even though TIN has a better precision compared to DEM.

The advancements in remote sensing technology have also greatly increased the application of hydrological modelling. Using remote sensing tools such as satellites and radar, acquisition of spatial data such as elevation has been simplified. El Bastawesy et al., (2009) used data collected from remote sensing and incorporated Manning's equation to calculate stream flow in carrying out a hydrological modelling along the River Nile in Egypt.

\subsection{StreamStats}

StreamStats is a USGS web-based GIS application developed using Arc Hydro tools and in cooperation with ESRI. The web app can be used to provide stream flow information such as peak discharge, maximum temperature, and average annual rainfall for an ungaged stream site for a selected pour point along a stream channel (Ward et al., 2016). The process involves either manually selecting a single point of interest on the map along a stream or by uploading pour points in the form of a shapefile. The stream flow and flood predictions are based on regression equations that vary from one region to another and provide peak estimates between a 7-day period and 500 years. The StreamStats watershed boundaries for California State are based on a 30m digital elevation model (DEM) and the streams are visible when the web app is zoomed in to the minimum scale of 16 .

The StreamStats map-based interface is accessible via URL https://streamstats.usgs.gov/ss/ on any browser and provides an interactive interface where a user can select a point to delineate. An error message is given if the point selected by the user is out of range or is not along the stream. 
The equations used to estimate flood frequency and discharge for streams in California by the StreamStats web app were derived from regional regression analyses. The data used in deriving the equations was collected for a period of more than 10 years from 771 stream gauges in California, as noted by Gotvald et al. (2012, p. 28). To derive these equations, the ordinary least square (OLS) regression technique was used during the exploratory analysis process. These regression equations that the StreamStats web app use to predict stream discharge and flood frequency have a standard error of between 214.2 and 856 percent (Gotvald et al., 2012, p. 28). However, as discussed by Gotvald et. al. (2012), the regression equations have limitations and cannot be used to predict flood frequency in urban areas where there's human influence such as constructions which modify the drainage system.

According to Gotvald et al. (2012), California is divided into different regions that use different sets of regional regression equations to predict floods. These regions are: Desert Region, Lahontan, North Coast, Central Coast and South Coast. 


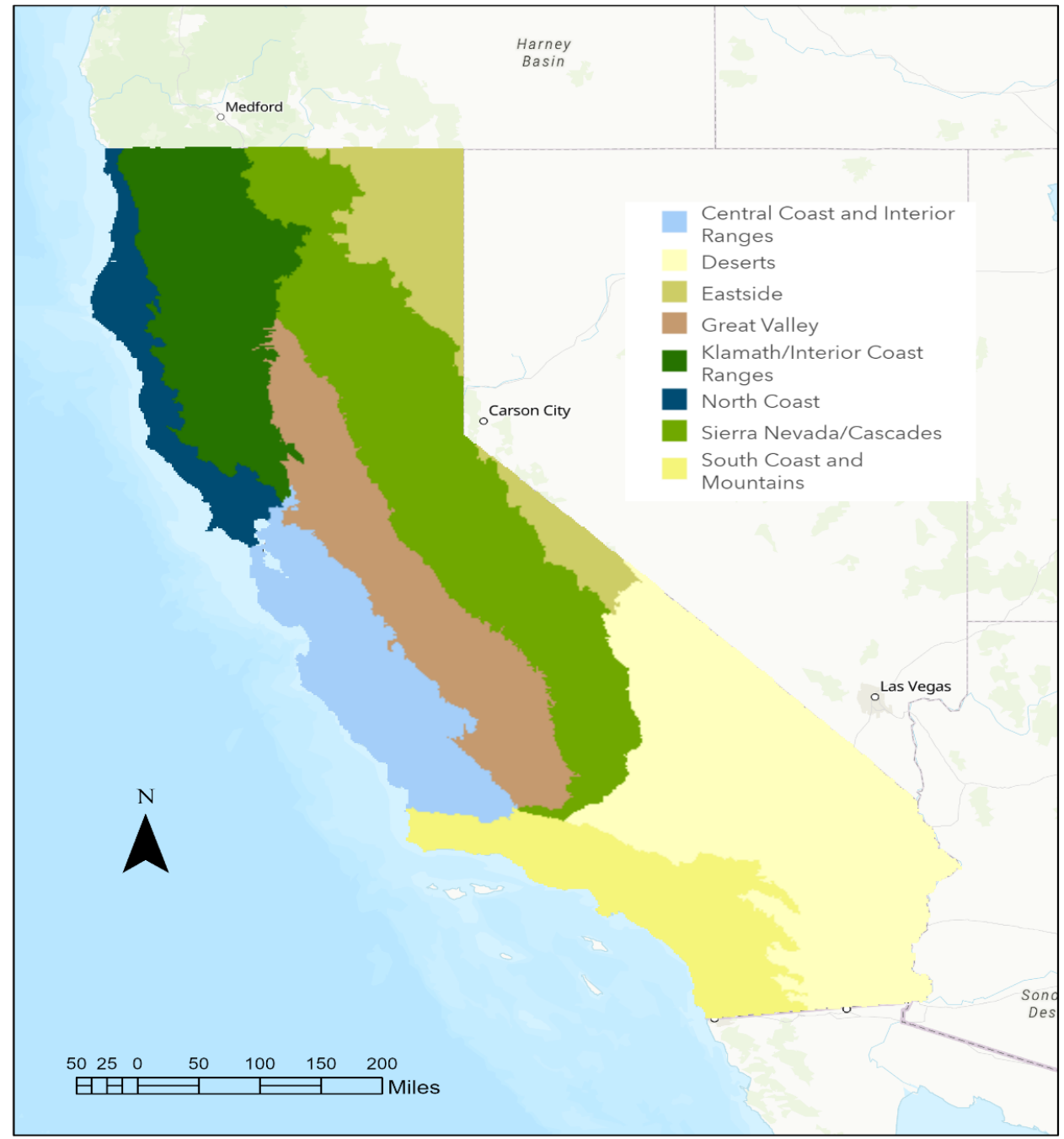

\section{Figure 2-2: StreamStats regions for California}

The following equation is used to predict flood in the desert region such as Joshua Tree National Park (JTNP):

$$
Q_{P}=a_{0}(D R N A R E A)^{b_{0}}(E L E V)^{c_{0}}(P R E C I P)^{d_{0}}
$$

Where:

$\mathrm{QP}_{\mathrm{P}}=$ is the P-percent annual exceedance probability flow in cubic feet per second. DRNAREA = drainage area measured in square miles.

ELEV = mean basin elevation measured in feet.

PRECIP = mean annual precipitation measured in inches. 
${ }_{0}^{\mathrm{a}},{ }_{0}^{\mathrm{b}},{ }_{0}^{\mathrm{c}}$ and ${ }_{0}^{\mathrm{d}}$ are coefficients.

According to Gotvald et. al. (2012), the use of percentage in Qp is preferred because it can show the probability or odds of flood estimate equaling or exceeding flood estimate for the year under consideration. This project shall use a 5-year peak discharge that has an annual exceedance probability of 20 and a standard error of prediction (SEP) of 226.

\subsection{Summary}

Because of the effects posed by global warming, flooding will continue to be a global challenge. In recognition of the dangers arising from such events, there has been a growing interest in research and investment in technology to measure precipitation. Examples of such technologies include use of radars and various hydrological modelling tools to represent such events in a computer world by use of simulations.

This chapter explored different surface runoff methods used in calculating direct surface overflow and explored existing hydrological modelling tools used. This chapter also discusses some of the limitations of methods used in calculating surface runoff. 


\section{Chapter 3 - Systems Analysis and Design}

To effectively manage the implementation of this project, planning and gathering of the project requirements was undertaken in conjunction with the client. This was essential to determine the system design best suited for this project and that would exactly meet the requirements of the project. This Chapter begins by reiterating the problem statement in section 3.1, section 3.2 discusses in greater details the project requirements both functional and non-functional. Project design is discussed in section 3.3. and a review of the project plan is discussed in section 3.4.

\subsection{Problem Statement}

Joshua Tree National Park (JTNP) is located in the Mojave Desert region and suffers regular flash floods during the rainy season. The project point of contact, Mr. Luke Sabala wanted a hydrological analysis for the North entrance of the park to be carried out with the objectives of determining the effectiveness of existing water diversion berms in the park and identifying areas where new ones needs to be installed. In addition, the project would also map out flood prone areas. The analysis results from this project would help in preparing a development guide for the park while protecting vulnerable structures from damages caused by floods.

\subsection{Requirements Analysis}

Requirements are vital in determining the overall success of any project. To ensure that the requirements for this project were well understood, regular meetings were arranged with Mr. Luke Sabala. These requirements were categorized into functional and nonfunctional. 


\subsubsection{System Design Functional Requirements}

Table 1 provides a summary of functional requirements and descriptions for this project.

Table 1: System Design Functional Requirements.

\begin{tabular}{|l|l|}
\hline Requirement & Description \\
$\begin{array}{l}\text { Generate DEM from LiDAR point cloud } \\
\text { for the area of study. }\end{array}$ & $\begin{array}{l}\text { A 3D elevation modelling the bare } \\
\text { earth terrain surface of the study } \\
\text { area. }\end{array}$ \\
$\begin{array}{l}\text { Derive peak discharge for streams. } \\
\begin{array}{l}\text { Produce 3D topological model in a } \\
\text { geodatabase showing simulating water } \\
\text { surface flow in the park. }\end{array}\end{array}$ & $\begin{array}{l}\text { Shis will be derived from } \\
\text { surface runoff in a 3D model. }\end{array}$ \\
\hline
\end{tabular}

\subsubsection{System Design Non-Functional Requirements}

These were software, hardware and supported data consideration requirements for the system used to carry out this project given the large size of input data that was used in this project. The system for this project needed to run on Windows operating system and ArcMap 10.6 desktop application. Table 2 summarizes the non-functional requirements for this project.

Table 2: System Design Non-Functional Requirements.

\begin{tabular}{|l|l|}
\hline Requirement & Description \\
Software & ArcMap 10.6 with Arc Hydro extension installed. \\
Operating system & $\begin{array}{l}\text { Windows 10, 64-bit operating system, 16 GB RAM } \\
\text { and 3.0 GHz processor speed. } \\
\text { Data format }\end{array}$ \\
& All the datasets must be in ArcGIS format. \\
\hline
\end{tabular}

Because of the large size of the LiDAR datasets, a higher capacity RAM was ideal for a better performance. The input data was required to be in an ArcMap supported 
format because this was the GIS software that was going to be used for this project. Another optional non-functional requirement was creating a geodatabase to store the project data.

\subsection{System Design}

The system design for this project was based on using an ArcMap desktop version 10.6 and existing Arc Hydro tools to carry out hydrological analysis. The stream discharge for streams of interest was derived from StreamStats web app and downloaded as zipped folder that contains Stream discharge for selected drainage points along a stream. All the input data required were clipped into the study area and projected to the NAD 19832011 UTM Zone $11 \mathrm{~N}$. The system design for this project is illustrated in Figure 3-1.

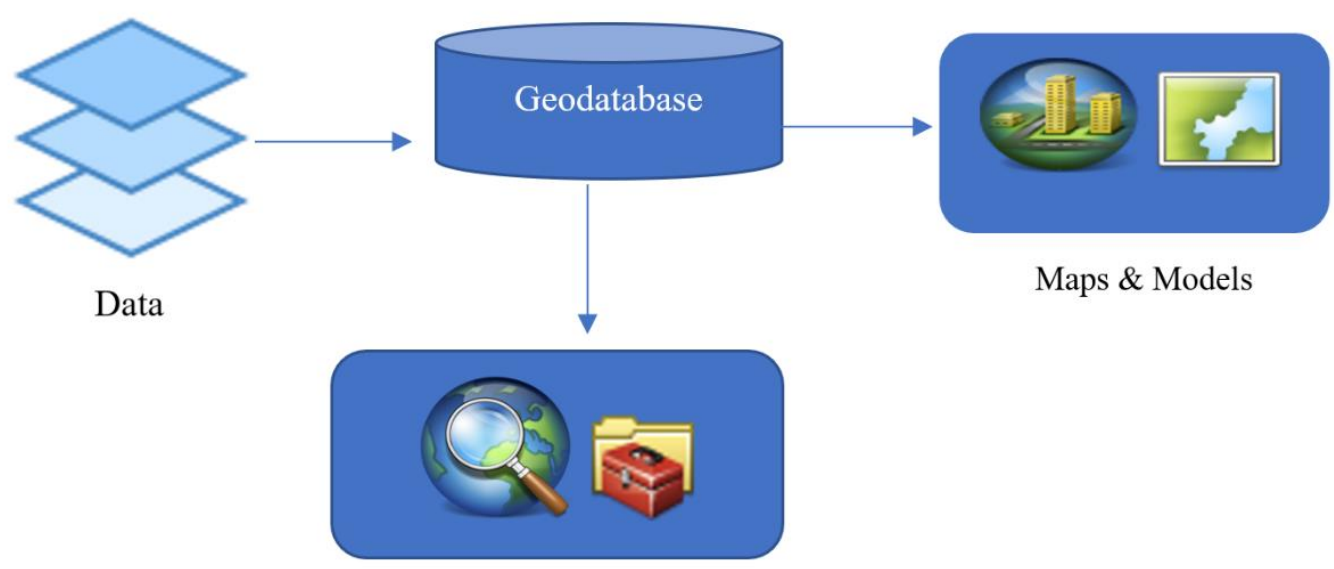

Arc Hydro tools

Figure 3-1: System Design.

\subsection{Project Plan}

The execution of this plan, within the constraints of time and resource allocation, required a formulation of a project plan from project inception to projection completion. This was very important in measuring progress and adjusting the plan appropriately. This project was broken down into four phases with tasks that were related in each phase. The following section outlines the project phases.

\subsubsection{Project Inception}

This was the first phase for this project, and it involved visiting the study area to understand the study area and determine the required datasets. This phase also consisted of gathering user requirements necessary from the client and eventually setting project objectives. The outcome from this phase constituted a project design. 


\subsubsection{Project Design}

Based on the project deliverables and requirements, this phase outlined the database model best suited for this project. Since the client is using ArcMap, the ArcGIS software and tools chosen for the project needed to be on the same version. Arc Hydro tools for topographic modelling were best suited for this project and consequently an Arc Hydro geodatabase model was adopted.

\subsubsection{Project Implementation}

This phase involved modifying the Arc Hydro default geodatabase schema to accommodate the data provided by the client for this project. Data preprocessing such as creating pyramids for raster datasets, reprojection and formatting both for raster and vector data was also done where necessary before data loading into project working directory. A topographical model was implemented in this phase after several iterations using Arc GIS Model Builder custom tools to get a suitable model. The output maps and models were stored as ArcMap MXD documents and scenes, respectively.

Although more time was spent on delineating the watershed using different DEM resolutions and comparing the results to watershed delineation boundaries from StreamStats, the overall project implementation did not change.

\subsubsection{Project Closure}

This was the last phase of this project. The project output - Geodatabase, Maps and 3D models were copied to a flash drive and handed over to the client.

\subsection{Summary}

This chapter presented an overview project workflow on how the project was executed right from the time the projected was incepted to completion. This chapter also discussed the system design functional and non-functional requirements that were critical to successfully carry out and implement the objectives and goals of this project. 


\section{Chapter 4 - Database Design}

This chapter discusses the design of the geodatabase and project data used in this project to arrive at the solution. Section 4.1 discusses the conceptual data model. Section 4.2 discusses the logical data model that was developed, section 4.3 discusses the data sources used, section 4.4 discusses the data scrubbing process, and finally section 4.5 provides a summary of this chapter.

\subsection{Conceptual Data Model}

The conceptual data model provides the relationship between different components used and how they are related to each other. The main goal of this project was to establish the effectiveness of water diversion berms in preventing further destruction of roads in the Northern entrance of the Joshua Tree National Park (JTNP). To solve this problem, several components were considered.

The components considered during this project included the precipitation, terrain, infiltration, and surface runoff. During the Monsoonal event, depending on the soil type, the rate of infiltration will vary and beyond a certain threshold, some of it flows as surface runoff into the flow channels and streams that exist in each watershed. These channels then drain this surface runoff downslope due to gravity. The unified modelling language (UML) diagram for these components is illustrated in Figure 4-1. 


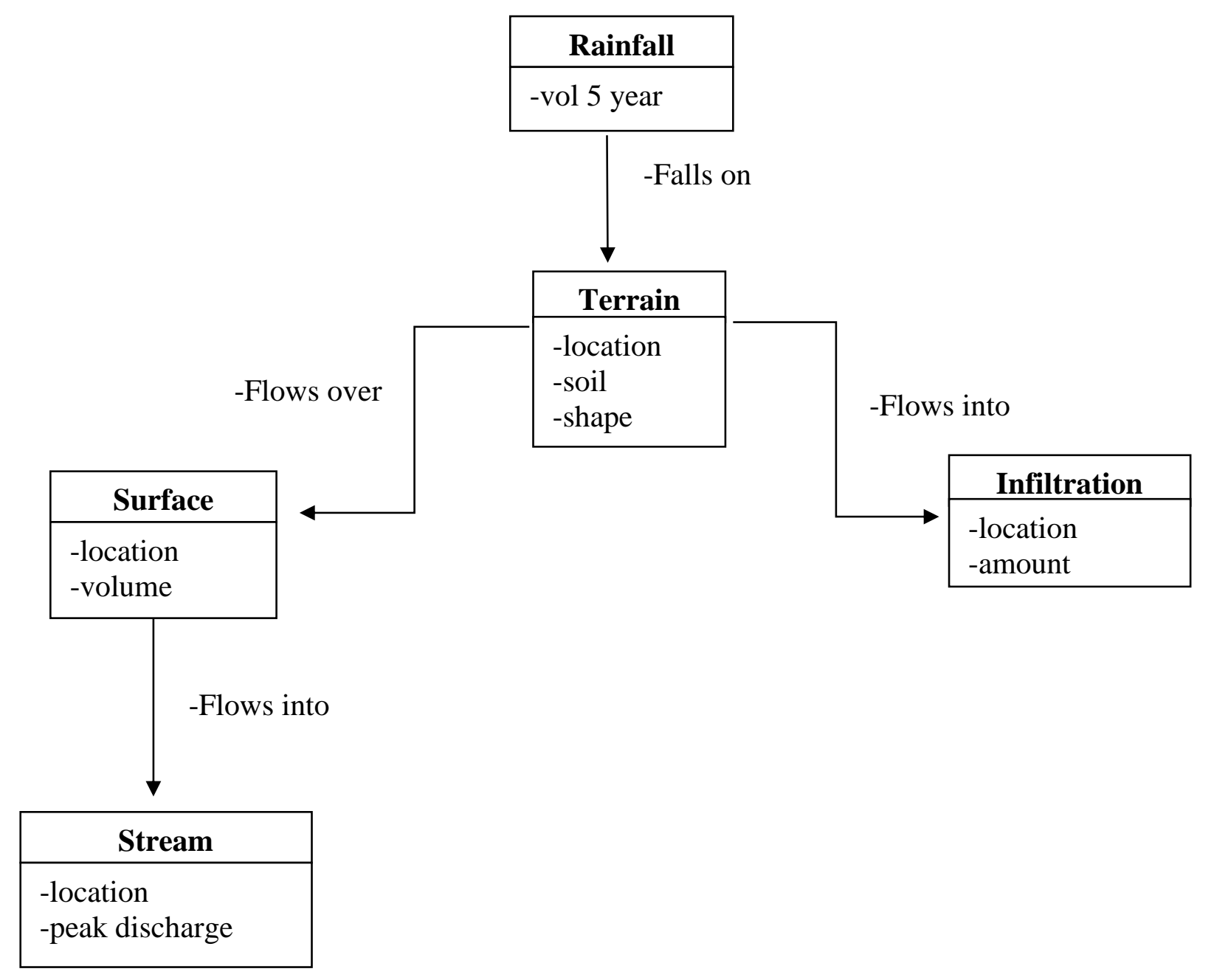

Figure 4-1: Conceptual model.

\subsection{Logical Data Model}

A logical data model transforms the conceptual data model into a detailed physical database. This project modified the default ESRI Arc Hydro geodatabase to get an appropriate schema to support the project needs of this project. One of the advantages of the ESRI geodatabase is the ability to organize this project's data in the database by theme.

Watershed boundary features, FLOWSTATS and CHARACTERISTICS tables from StreamStats were stored in a separate geodatabase (GDB) for easy organization. A $0.5 \mathrm{~m}$ 
raster DEM that was derived from LiDAR point cloud was stored outside a geodatabase. Terrain preprocessing output data from the DEM were stored in the main folder for this project. Figure 4-2 shows the overall logical database architecture.

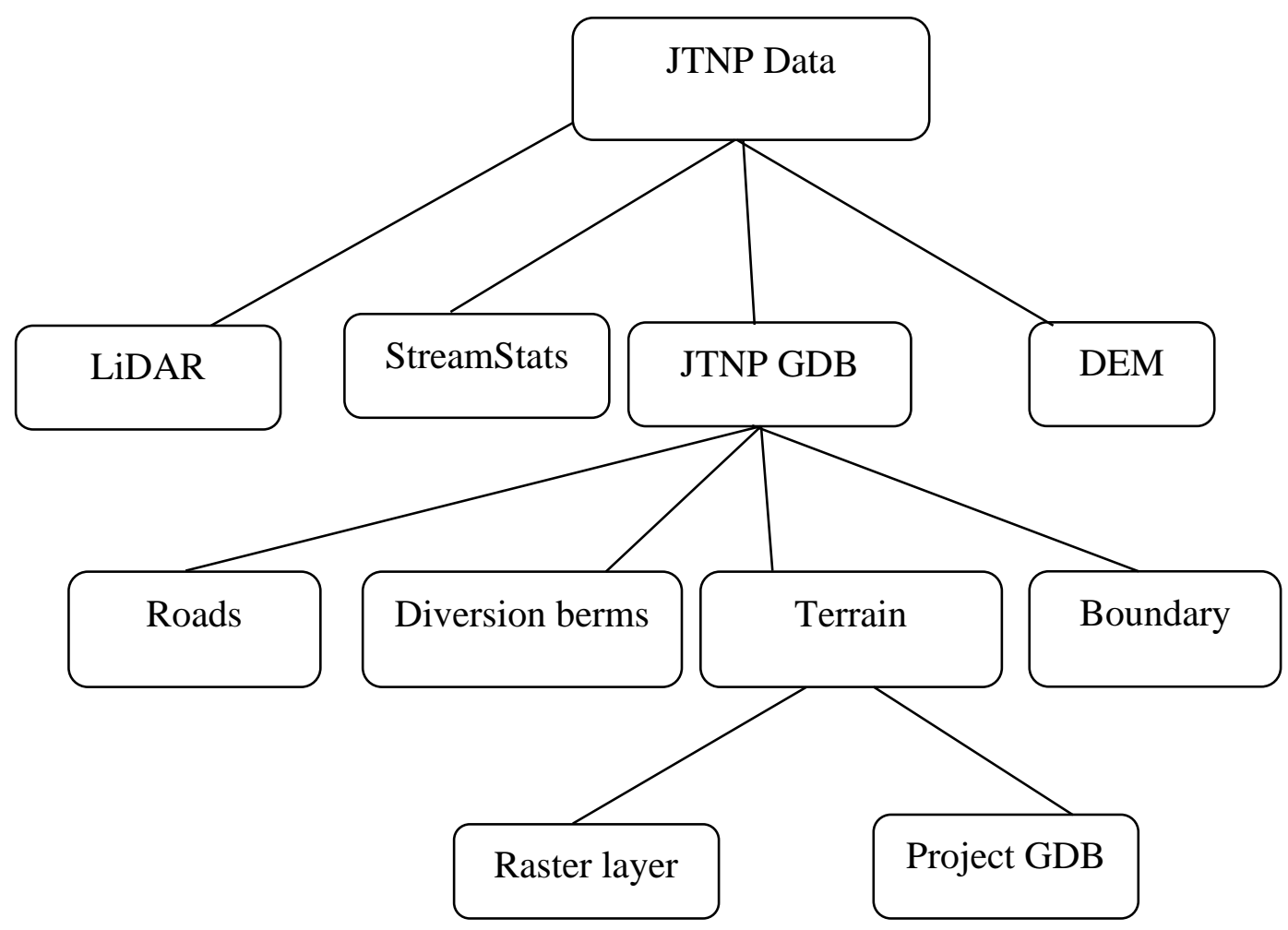

Figure 4-2: Logical model.

The terrain folder contains terrain preprocessing outputs derived from the DEM using the Arc Hydro terrain preprocessing tools. These outputs include layers and rasters that contain catchment, flow direction, stream, and streamlinks. The project geodatabase contained features such as watersheds, watershed points, adjacent catchments, drainage points, and drainage lines.

\subsection{Data Sources}

Data for this project was from two sources: the client and the USGS StreamStats web application. The LiDAR point cloud data, roads, diversion berms, and park boundaries were all obtained from JTNP. Watershed boundaries, flowstats and characteristics were obtained from the StreamStats delineation web app that uses ESRI Arc Hydro tools to delineate watersheds and regional regression equations to estimate peak discharge for streams. Table 3 summarizes the sources for all the data used in this project. 
Table 3: Data Sources.

\begin{tabular}{|l|l|l|}
\hline Data & Format & Source \\
\hline LiDAR & las & client \\
\hline Roads & vector & client \\
\hline Peak discharge & table & USGS \\
\hline Watershed & vector & USGS \\
\hline Park boundary & vector & client \\
\hline Streams & vector & USGS \\
\hline
\end{tabular}

\subsection{Data Scrubbing and Loading}

The original datasets used for this project had a large extent and needed to be clipped to the northern entrance of JTNP. To derive the DEM for the study area, additional LiDAR data processing was needed. An intermediate temporary geodatabase was created to store the preprocessing output. All the data provided by the client did not need to be reprojected, as it was in the NAD 19832011 UTM Zone 11N projection. The next section will discuss data preprocessing that was done for input data.

\subsubsection{Elevation Data Preprocessing}

The elevation data needed to be of a high resolution since it was being derived from a raw LiDAR point cloud data. In total, the study area had $98 \mathrm{LiDAR}$ point cloud files with approximately 17 points per square meter. To preprocess the LiDAR data, a LiDAR dataset was created that contained all $98 \mathrm{LiDAR}$ files that covered the northern entrance of JTNP.

Since a LAS dataset cannot be stored in a geodatabase, it was stored in a folder within the main project folder. To derive a DEM from the LAS dataset, one assumption made was that the ground return registered in the LiDAR data represented the bare ground surface for the area under study for this project. To derive a DEM raster from the LiDAR dataset, a LAS dataset to raster ArcGIS tool was used with a sampling distance of $1 \mathrm{~m}$. A default $\mathrm{z}$ value of one was used during the transformation. The resulting DEM had a resolution of $1 \mathrm{~m}$ and 14000 rows by 7000 columns, and this raster was stored in a DEM folder within the main project work directory. Additional DEMs with resolutions of $0.2 \mathrm{~m}, 0.5 \mathrm{~m}$ and $5 \mathrm{~m}$ were also created in this step for accuracy assessment checks.

\subsubsection{Depressionless DEM Processing}

This was the first processing that was applied to the DEMs used for this project. This process involved creating a depressionless surface raster that was used for the subsequent 
terrain preprocessing step. The DEMs did not contain sinks and it was the desired input when determining the flow surface flow direction.

The presence of sinks in a DEM could result in an erroneous flow direction output raster when determining flow direction. This can be resolved by filling any sinks in the DEM before determining the flow direction of surface water. Using the Arc Hydro fill tool, the tool uses the raw DEM as input data and produces a depressionless Hydro DEM that was used in terrain preprocessing.

\subsubsection{Terrain Preprocessing}

A basic dendritic terrain processing was applied to a Hydro DEM for the study area. This is because the area had no known sink or stream information based on the data provided. An attempt to use a $0.2 \mathrm{~m}$ resolution Hydro DEM failed. Because three different DEMs resolutions were used, instead of manually delineating each DEM, an ArcGIS model was used to iterate through the DEMs and store each output from delineation in an appropriate subfolder.

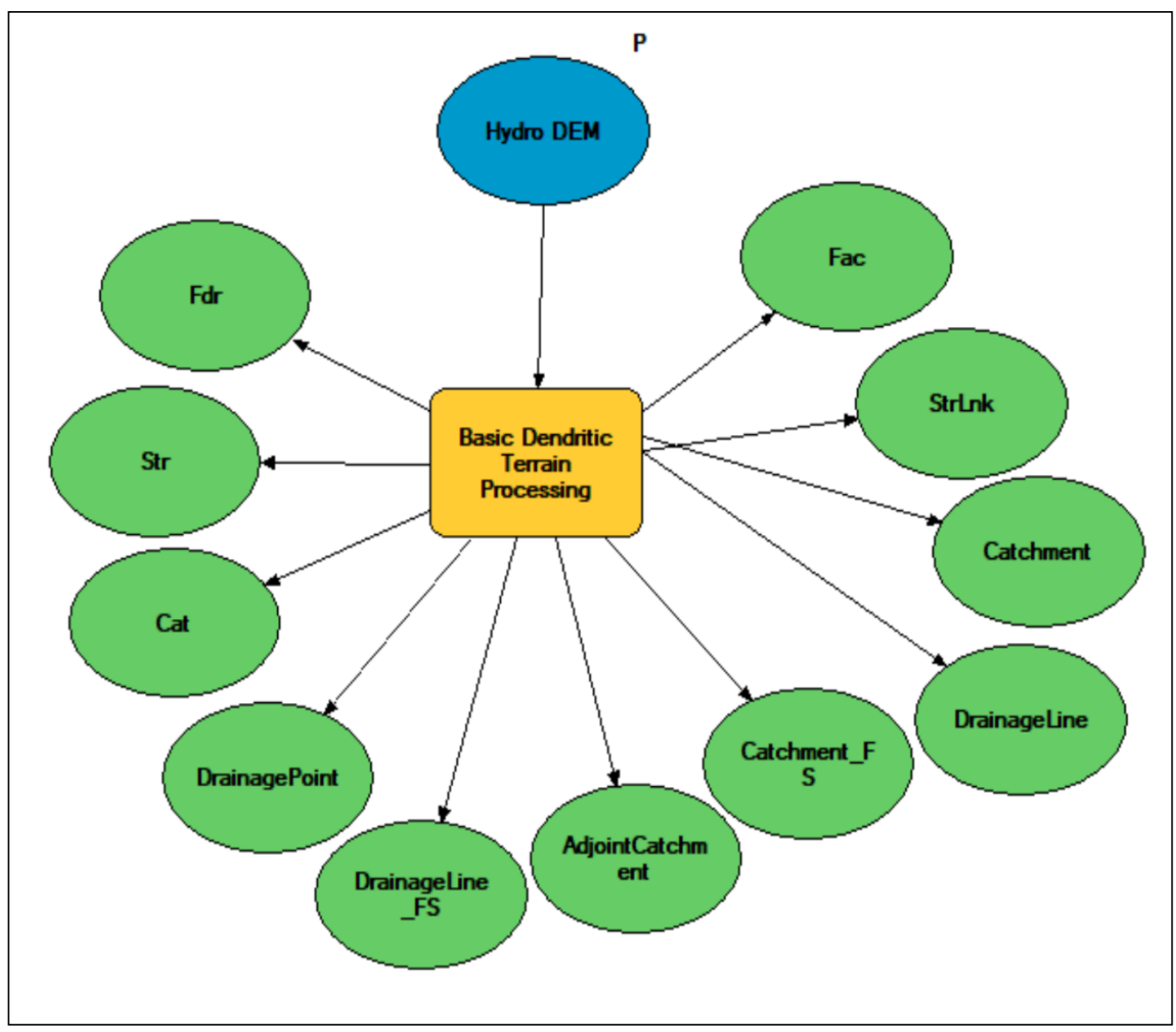

Figure 4-3: Terrain preprocessing model.

The terrain preprocessing tool produced vector data catchment points and drainage lines that were important in determining the drainage lines in the study area. Other 
outputs from this process include catchment, adjacent catchments, streams and streamlinks raster files.

\subsubsection{StreamStats Discharge}

StreamStats is a web based application by USGS that uses ESRI Arc Hydro tools to delineate watersheds and regional regression equations to estimate peak discharge for a selected single point, or uses batch processing for several drainage points, but this function is limited to 200 point locations where flow estimate are desired. Batch file points need to be a shapefile format containing four files: PRJ, SHX, SHP and DBF.

The output from StreamStats is a zipped geodatabase that contains watershed boundary vector file, FLOWSTATS and CHARACTERISTICS geodatabase tables.

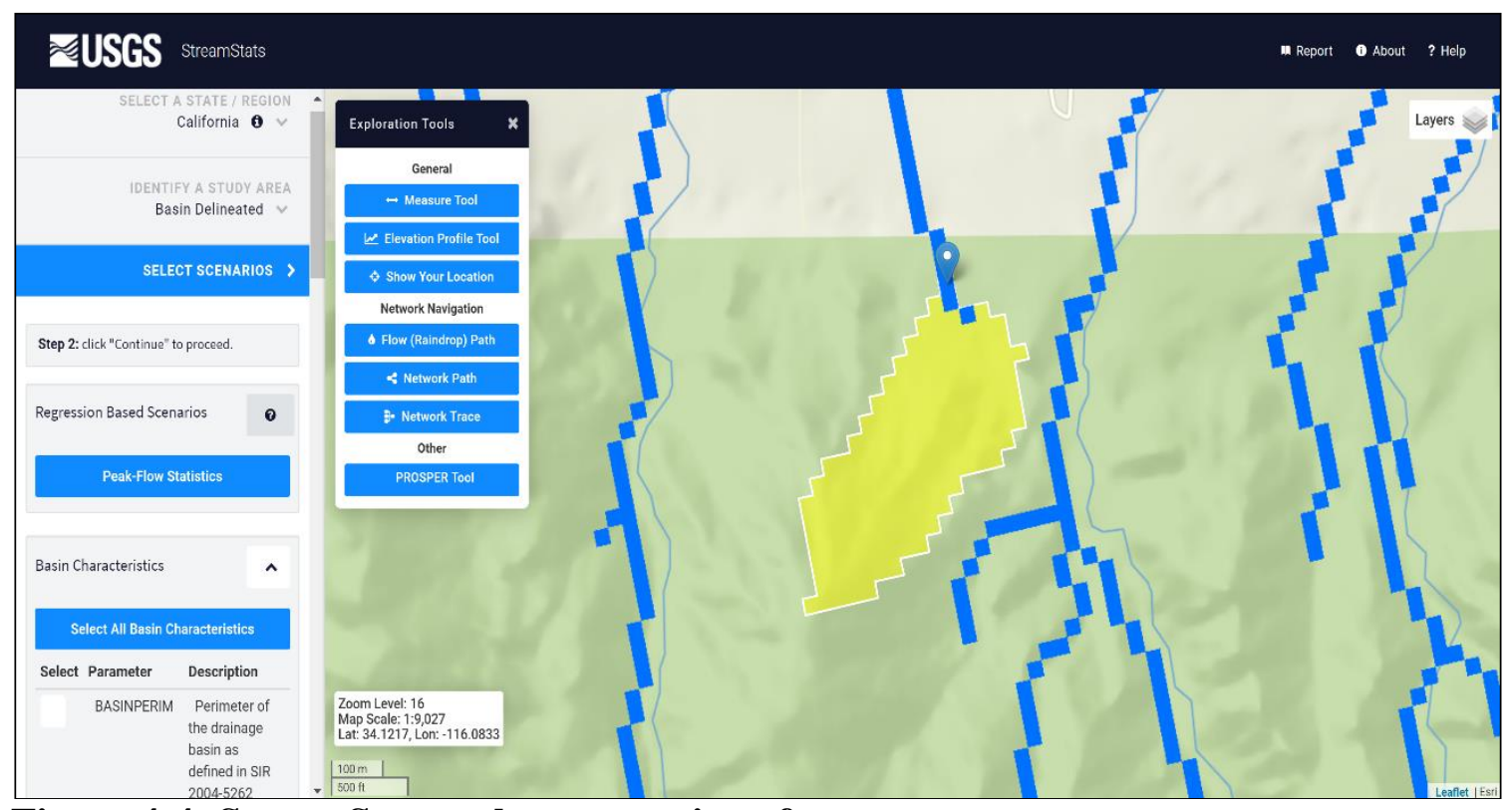

Figure 4-4: StreamStats web app user interface.

The data from StreamStats needed to be projected from NAD_1983_Albers to NAD 19832011 UTM Zone 11N.

\subsection{Summary}

This chapter addressed the database design used for this project. The conceptual data model and logical data model were also discussed. This chapter also discussed various input data used such as LiDAR data, StreamStats data, roads, and water diversion berms. The conceptual design was then transformed into a physical logical data model used for analysis process for this project. Additional data preprocessing tasks were also highlighted in this chapter. 


\section{Chapter 5 - Implementation}

This chapter covers the methodologies and workflows that were used in determining the efficiency of existing water diversion barriers and suggests new locations where new barriers should be built. The workflow involved delineating the basin to determine the drainage lines and establishing the peak discharge in the selected streamline.

\subsection{Elevation Preprocessing}

This was the first task that needed to be accomplished to understand the elevation of the study area. The elevation data provided by the client was a LiDAR point cloud data with approximately $17 \mathrm{LiDAR}$ points per square meter. Figure 5-1 shows the boundary extent of the LiDAR point cloud. 


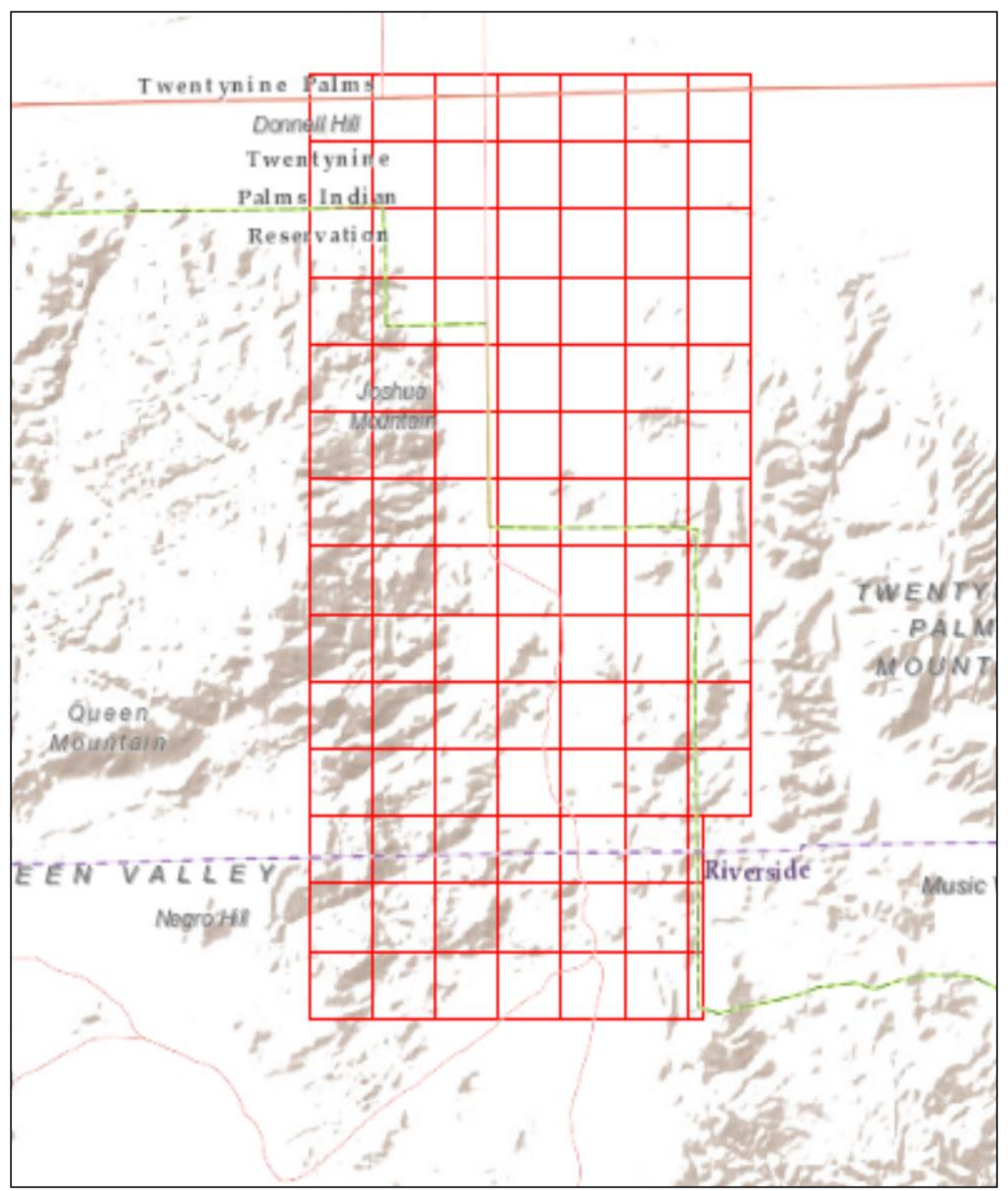

Figure 5-1 : LiDAR point cloud extent for the Northern entrance.

In order to have a comprehensive elevation model of the study area, it was critical to establish several elevation raster files with different resolutions for feature comparison purposes. Different resolutions produce slightly different shape and length for streams when delineated and it was better to have several resolutions from which the best that represents the streams of interest can be selected from.

The workflow for elevation processing involved creating a LiDAR Data Exchange File (LAS) dataset within the project folder because a LiDAR dataset cannot be stored within a geodatabase. Ninety-eight individual LiDAR files provided by the client were then loaded into the LAS dataset folder ready for elevation processing. The LiDAR point cloud was filtered to ground return based on the assumption that this represented the ground surface terrain.

To ensure that the locational accuracy of berms was well obtained, there was a need to create digital elevation models of different resolutions to and use a DEM that correctly represented the location and flow direction of the streams in the park. As a result, float type digital elevation models (DEM) of $0.2 \mathrm{~m}, 0.5 \mathrm{~m}, 1 \mathrm{~m}$ and $5 \mathrm{~m}$ were created using the LAS dataset to raster ArcGIS tool. Average cell assignment was used to interpolate the 
cloud points to raster cell values. The output rasters from this process were stored in a DEM folder for this project for easy data organization.

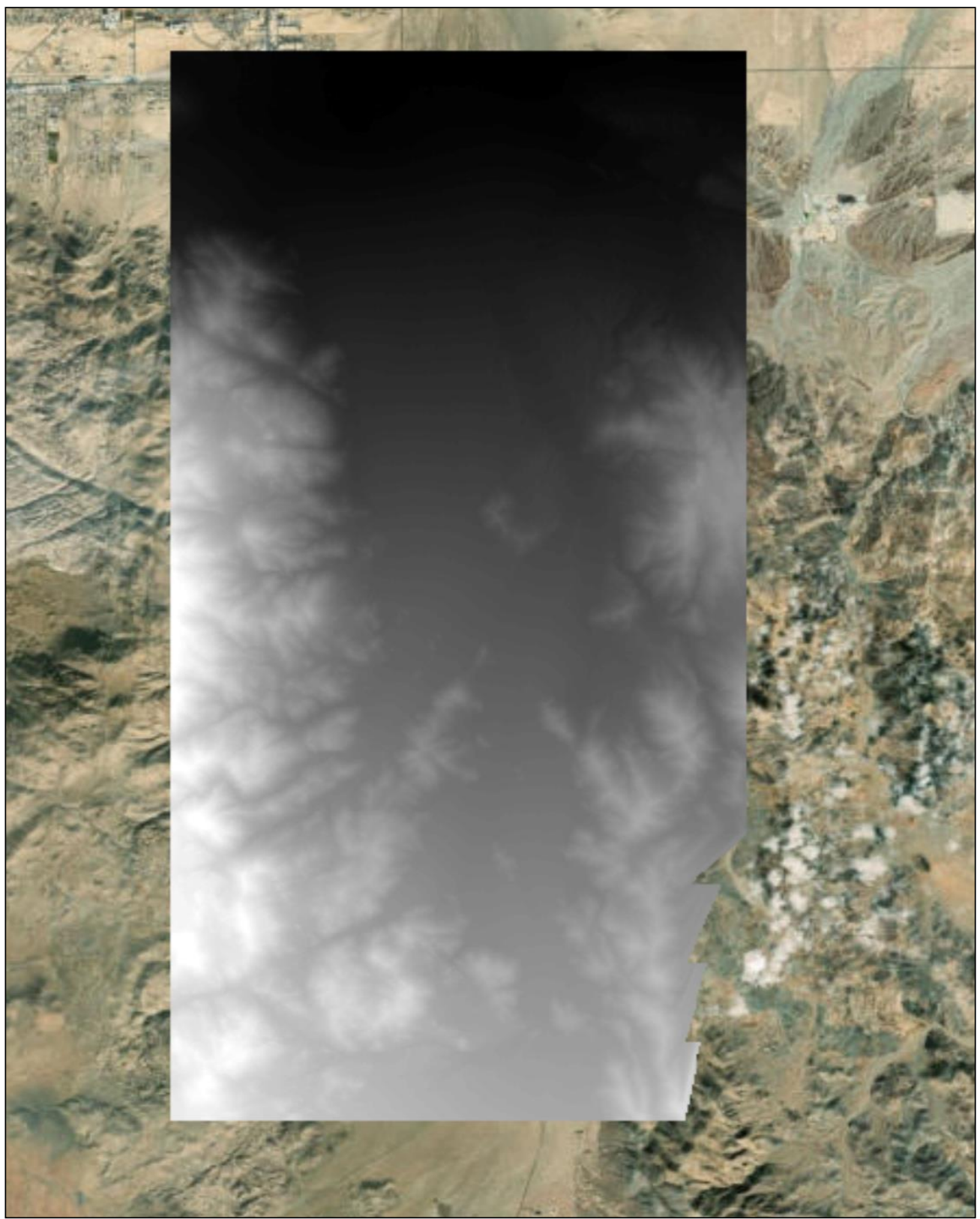

Figure 5-2: A 0.2m DEM generated from LiDAR point cloud data.

\subsection{Terrain Preprocessing and Delineation}

Terrain preprocessing and watershed delineation using Arc Hydro tools required several preprocessing steps. Because of the several DEM resolutions used, an ArcGIS model was used to iterate through the DEMs input data and using inline substitution for the resulting preliminary datasets. The steps undertaken were based on a dendritic drainage pattern with no information about sinks and streams in the study area. 


\subsubsection{Fill Sinks}

This was the first step in creating a Hydro DEM to be used in the subsequent terrain preprocessing steps. A sink in a raster cell exists where the raster cell value is smaller than the surrounding raster cell values, and therefore does not have a known flow direction. This step eliminated the problems created by sinks when determining the flow direction of surface water. The resulting depressionless Hydro DEM is ideal for terrain preprocessing steps as it minimizes the risk of having an incorrect flow direction raster.

The fill sinks process was applied to all the different resolution DEMs that were generated using the Arc Hydro fill sinks tool. Higher resolutions, especially the $0.2 \mathrm{~m}$ DEM, took more time to process. The resulting Hydro DEMs were stored in a separate folder within the project folder. Figure 5-3 shows the fill sinks tool used for this step.

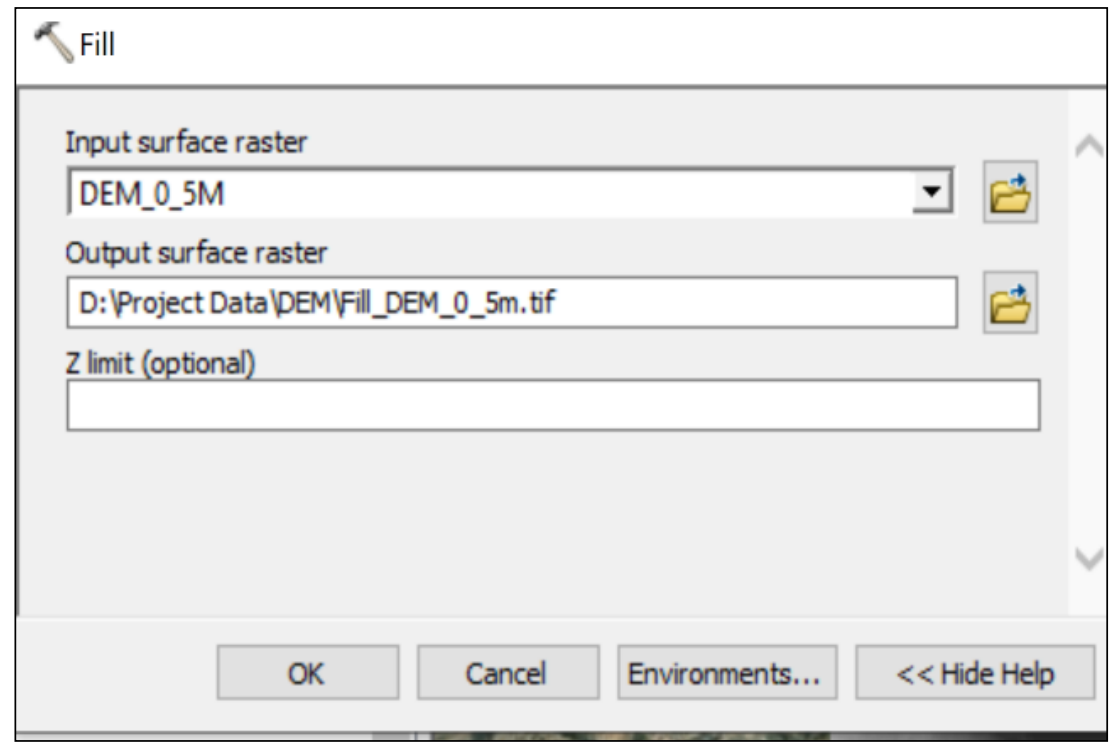

Figure 5-3: Fill sinks.

\subsubsection{Terrain Preprocessing}

This step used the Hydro DEMs from the previous step as the input for terrain preprocessing tasks. The main purpose of this step was to ensure a hydrologically correct DEM. The output from this process was related layers that could be used in other hydrological analysis processes, thus cutting down the time required for other analyses such as drainage area characterization.

The terrain preprocessing was carried out for all the DEM resolutions, but this task failed for the DEM with a resolution of $0.2 \mathrm{~m}$, even after multiple attempts. Despite the long processing time taken for $0.5 \mathrm{~m}, 1 \mathrm{~m}$, and $5 \mathrm{~m}$ DEMs, this process was completed successfully. As a result, the $0.2 \mathrm{~m}$ DEM resolution was dropped from this project.

Of great importance for this project was determining the flow direction in the study area, drainage lines and points, and watershed boundaries, all in relation to the location of water diversion berms. Thus, basin processing was important in establishing the drainage boundaries that existed within the study area and surrounding areas. As such, it was of great importance to try and be as accurate as possible with their locations as the diversion 
berms are meant to divert these channels from directly hitting the road by increasing their channel length and thus reducing the flow velocity in those channels. Figure 5-4 illustrates the terrain preprocessing workflow model builder that was used.

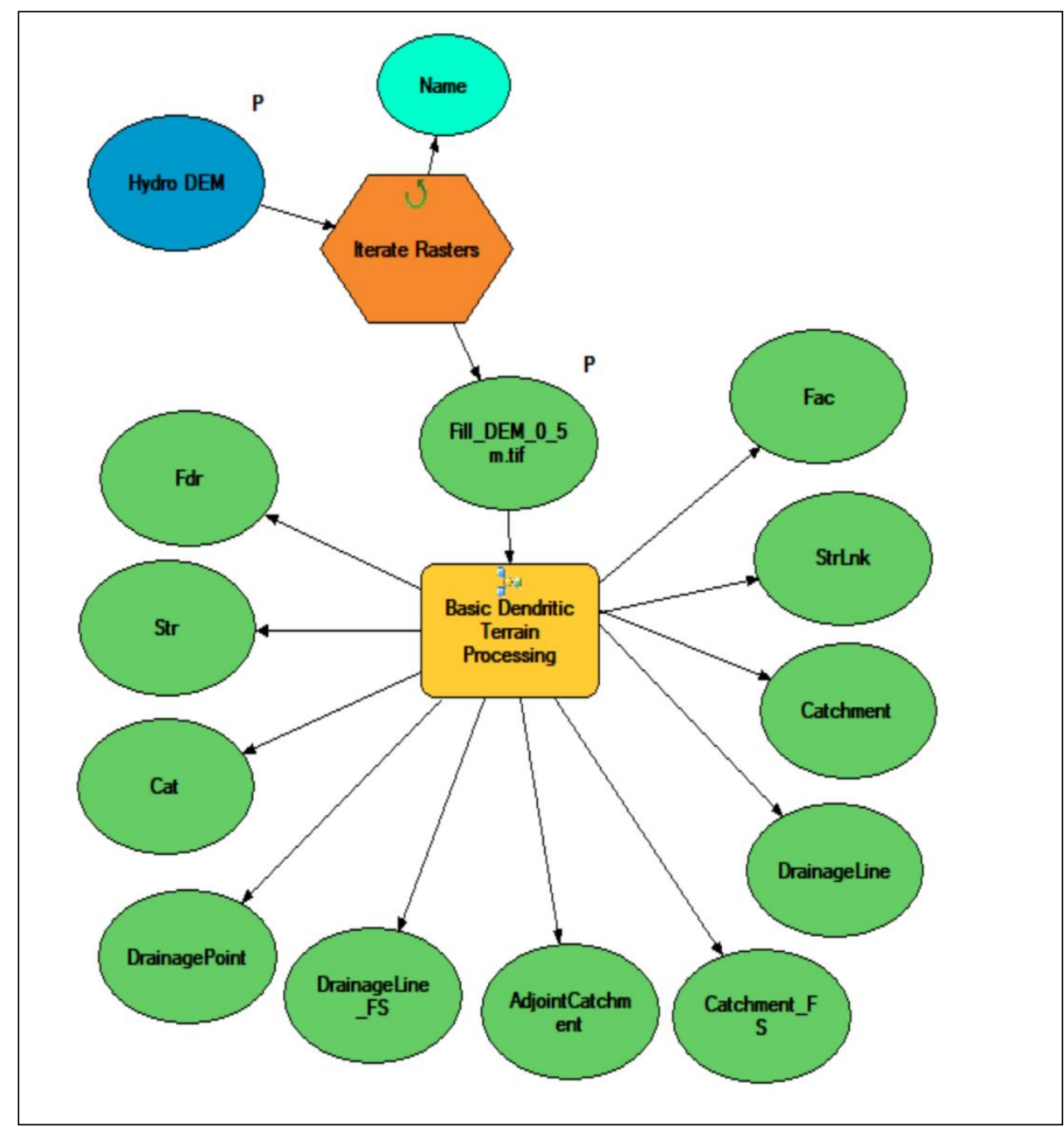

Figure 5-4: Terrain preprocessing workflow.

Basic dendritic terrain preprocessing was ideal because all the drainage characteristics are solely derived from the DEM and no prior information about sinks and streams is known. The resulting drainage points layers from terrain preprocessing constituted the input to be used in deriving discharge values from StreamStats at those particular points. Drainage points represents the pour points where water flows out from a drainage area and is thus the lowest point in the watershed.

\subsection{StreamStats Peak Discharge}

StreamStats proved to be a good source for calculating discharge and peak flow volume for selected streams in the park. Although StreamStats batch processing is limited to 200 
pour points in a study area, the results were very useful in understanding the amount of water in each channel that a diversion berm is supposed to divert. Generally, each watershed drainage line has more surface runoff or discharge flowing through them as they drain the watershed downslope. To effectively manage flash flood damages on Park Blvd Road in Joshua Tree National Park, the correct approach was to understand the drainage line pattern and discharge for those streams reaching the road.

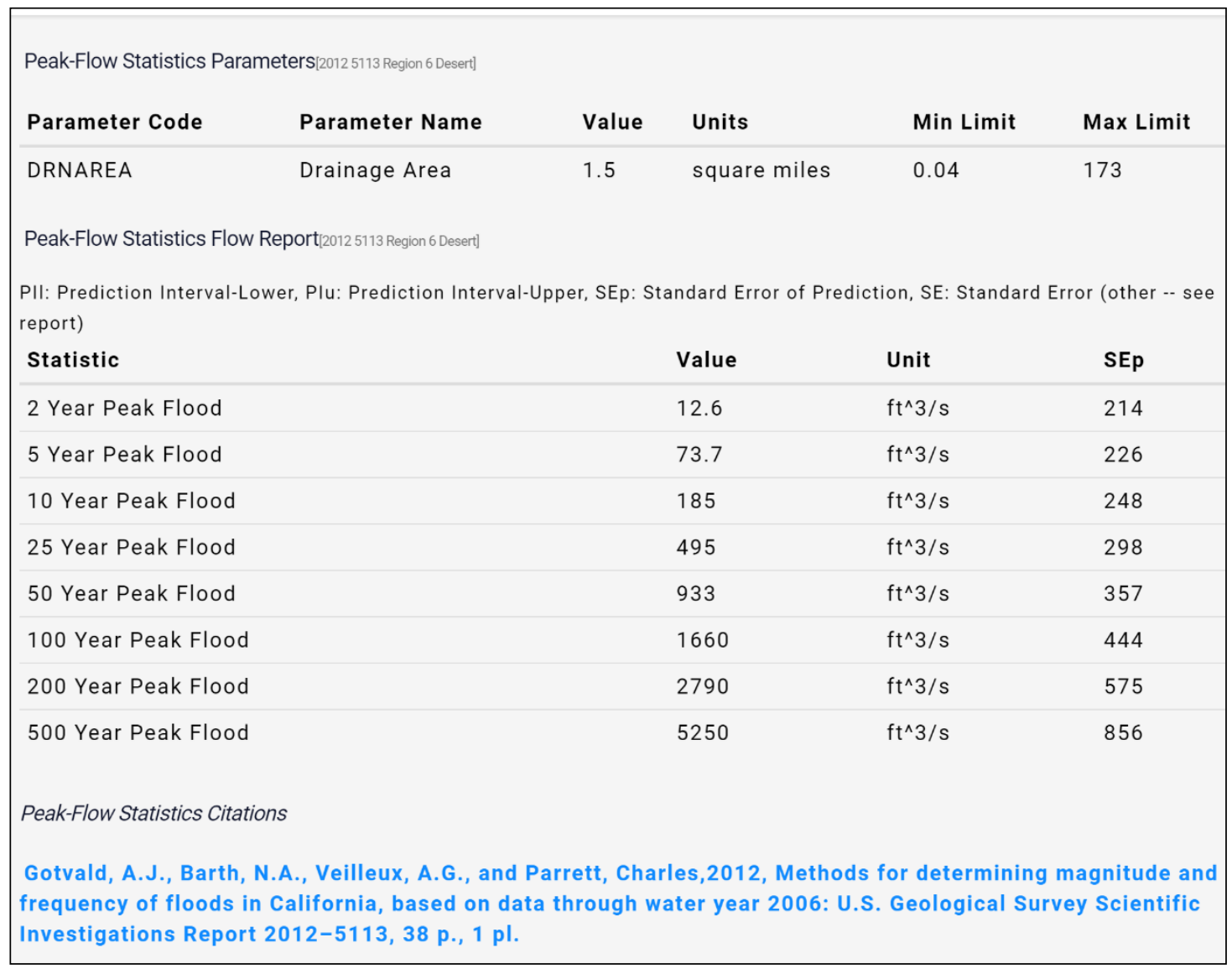

\section{Figure 5-5: An excerpt from StreamStats report.}

StreamStats provides options for delineating a single drainage point or a batch of points not exceeding 200, using the batch processing option. The number of drainage points derived from terrain preprocessing task were used to derive stream discharge for the study area. Figure 5-6 shows the user interface for uploading batch drainage points and the flow stats that are available. 


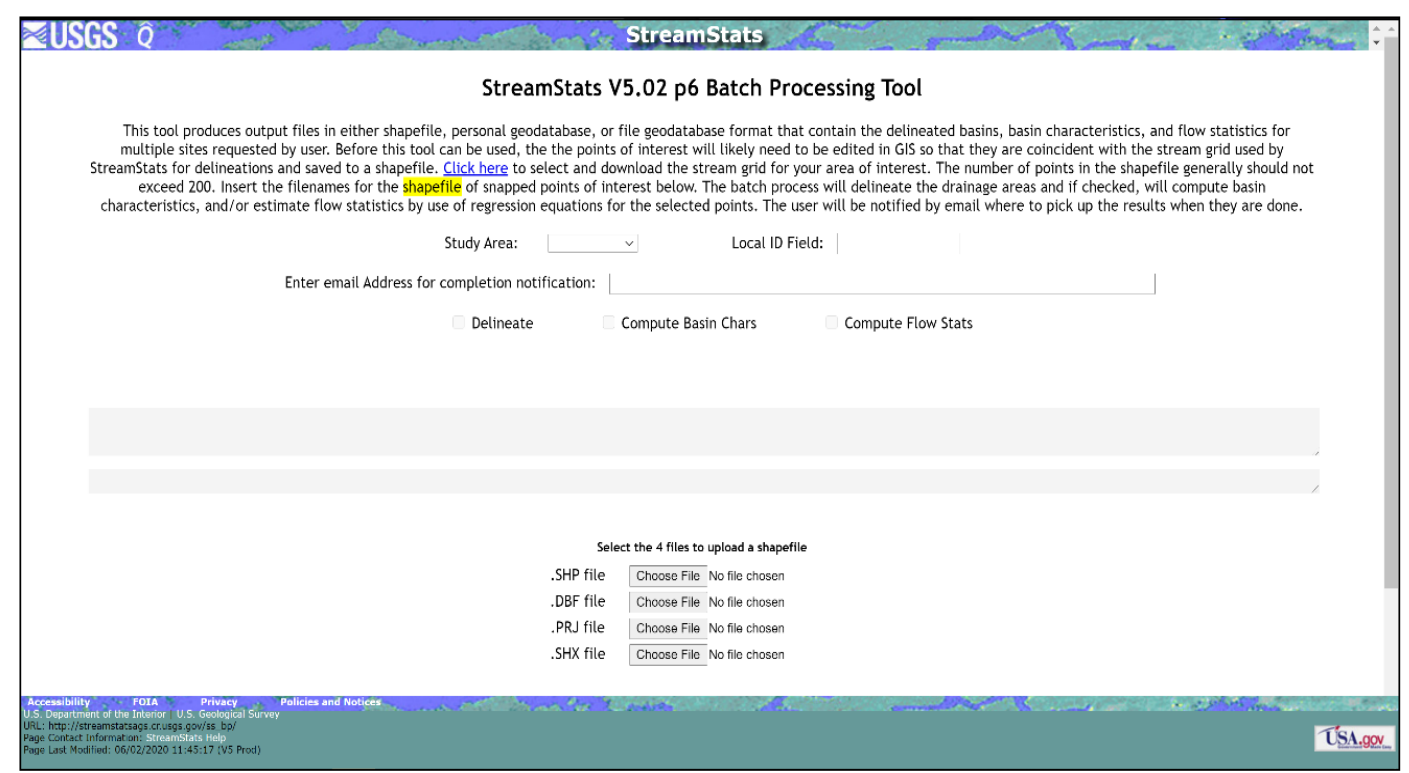

Figure 5-6: StreamStats batch processing tool user interface.

For batch processing the StreamStats on average took four hours, depending on the number of drainage points used for this project. The results from this process constituted the input to be used to understand the watersheds that have a high 5-year peak discharge that directly flows across Park Blvd in JTNP.

Figure 5-7 shows a batch StreamStats FLOWSTATS report from batch processing derived from drainage points derived from terrain preprocessing step. 


\begin{tabular}{|c|c|c|c|c|c|c|c|c|}
\hline 1 & gc1534 & 2012_5113_Region_6_Desert & 100 & 0.05 & PK5 & 5 Year Peak Flood & 13.2 & cubic feet per second \\
\hline 2 & gc1534 & 2012_5113_Region_6_Desert & 100 & 0.29 & PK5 & 5 Year Peak Flood & 32.1 & cubic feet per second \\
\hline 3 & gc1534 & 2012_5113_Region_6_Desert & 100 & 0.21 & PK5 & 5 Year Peak Flood & 27.2 & cubic feet per second \\
\hline 6 & gc1534 & 2012_5113_Region_6_Desert & 100 & 0.12 & PK5 & 5 Year Peak Flood & 20.5 & cubic feet per second \\
\hline 7 & gc1534 & 2012_5113_Region_6_Desert & 100 & 0.12 & PK5 & 5 Year Peak Flood & 20.5 & cubic feet per second \\
\hline 8 & gc1534 & 2012_5113_Region_6_Desert & 100 & 0.0 & PK5 & 5 Year Peak Flood & 0.0 & cubic feet per second \\
\hline 9 & gc1534 & 2012_5113_Region_6_Desert & 100 & 0.0 & PK5 & 5 Year Peak Flood & 0.0 & cubic feet per second \\
\hline 10 & gc1534 & 2012_5113_Region_6_Desert & 100 & 0.95 & PK5 & 5 Year Peak Flood & 58.5 & cubic feet per second \\
\hline 11 & gc1534 & 2012_5113_Region_6_Desert & 100 & 0.95 & PK5 & 5 Year Peak Flood & 58.5 & cubic feet per second \\
\hline 12 & gc1534 & 2012_5113_Region_6_Desert & 100 & 0.0 & PK5 & 5 Year Peak Flood & 0.0 & cubic feet per second \\
\hline 17 & gc1534 & 2012_5113_Region_6_Desert & 100 & 0.18 & PK5 & 5 Year Peak Flood & 25.2 & cubic feet per second \\
\hline 18 & gc1534 & 2012_5113_Region_6_Desert & 100 & 0.37 & PK5 & 5 Year Peak Flood & 36.3 & cubic feet per second \\
\hline 19 & gc1534 & 2012_5113_Region_6_Desert & 100 & 0.37 & PK5 & 5 Year Peak Flood & 36.3 & cubic feet per second \\
\hline 20 & gc1534 & 2012_5113_Region_6_Desert & 100 & 0.04 & PK5 & 5 Year Peak Flood & 11.8 & cubic feet per second \\
\hline 21 & gc1534 & 2012_5113_Region_6_Desert & 100 & 0.04 & PK5 & 5 Year Peak Flood & 11.8 & cubic feet per second \\
\hline 22 & gc1534 & 2012_5113_Region_6_Desert & 100 & 0.18 & PK5 & 5 Year Peak Flood & 25.2 & cubic feet per second \\
\hline 23 & gc1534 & 2012_5113_Region_6_Desert & 100 & 0.18 & PK5 & 5 Year Peak Flood & 25.2 & cubic feet per second \\
\hline 24 & gc1534 & 2012_5113_Region_6_Desert & 100 & 3.67 & PK5 & 5 Year Peak Flood & 116 & cubic feet per second \\
\hline 25 & gc1534 & 2012_5113_Region_6_Desert & 100 & 3.67 & PK5 & 5 Year Peak Flood & 116 & cubic feet per second \\
\hline 26 & gc1534 & 2012_5113_Region_6_Desert & 100 & 0.0 & PK5 & 5 Year Peak Flood & 0.0 & cubic feet per second \\
\hline 27 & gc1534 & 2012_5113_Region_6_Desert & 100 & 0.0 & PK5 & 5 Year Peak Flood & 0.0 & cubic feet per second \\
\hline 28 & gc1534 & 2012_5113_Region_6_Desert & 100 & 1.09 & PK5 & 5 Year Peak Flood & 62.7 & cubic feet per second \\
\hline 29 & gc1534 & 2012_5113_Region_6_Desert & 100 & 1.09 & PK5 & 5 Year Peak Flood & 62.7 & cubic feet per second \\
\hline 30 & gc1534 & 2012_5113_Region_6_Desert & 100 & 0.0 & PK5 & 5 Year Peak Flood & 0.0 & cubic feet per second \\
\hline 39 & gc1534 & 2012_5113_Region_6_Desert & 100 & 0.06 & PK5 & 5 Year Peak Flood & 14.5 & cubic feet per second \\
\hline 40 & gc1534 & 2012_5113_Region_6_Desert & 100 & 4.87 & PK5 & 5 Year Peak Flood & 134 & cubic feet per second \\
\hline 41 & gc1534 & 2012_5113_Region_6_Desert & 100 & 4.87 & PK5 & 5 Year Peak Flood & 134 & cubic feet per second \\
\hline 42 & gc1534 & 2012 5113 Region_6 Desert & 100 & 0.43 & PK5 & 5 Year Peak Flood & 39.1 & cubic feet per second \\
\hline
\end{tabular}

Figure 5-7: StreamStats Flow statistics table.

\subsection{Summary}

The methodologies for processing elevation and terrain preprocessing, using Arc Hydro tools and determining stream discharge for drainage points of interest using StreamStats web application, were reviewed in this chapter. Chapter 6 will discuss the findings from this chapter and recommendations that can be implemented to protect Park Blvd and other buildings along the streams in JTNP. 


\section{Chapter 6 - Results and Analysis}

The primary goal of this project was to establish the efficiency of existing water berms in the Joshua Tree National Park (JTNP) and recommend areas that need to be reinforced based on hydrological analysis results using StreamStats and Arc Hydro tools. This chapter will discuss the findings from the watershed delineation process from the different digital elevation model (DEM) resolutions used. Efficiency of existing water diversion berms, additional recommendations to protect Park Blvd, and potential sites that could use diversion berms are also discussed in this chapter.

\subsection{Terrain Preprocessing Results}

The study area for this project is located in the Northern entrance of JTNP. Terrain preprocessing was based on three DEM resolutions: $0.5 \mathrm{~m}, 1 \mathrm{~m}$ and $5 \mathrm{~m}$. After several unsuccessful attempts to use a $0.2 \mathrm{~m}$ DEM for preprocessing, this DEM was dropped.

Results from terrain preprocessing indicated that the area had a dendritic drainage pattern which flowed northwards in the study area. Figures 6-1, 6-2 and 6-3 shows output drainage patterns from the three DEMs used in terrain preprocessing. 


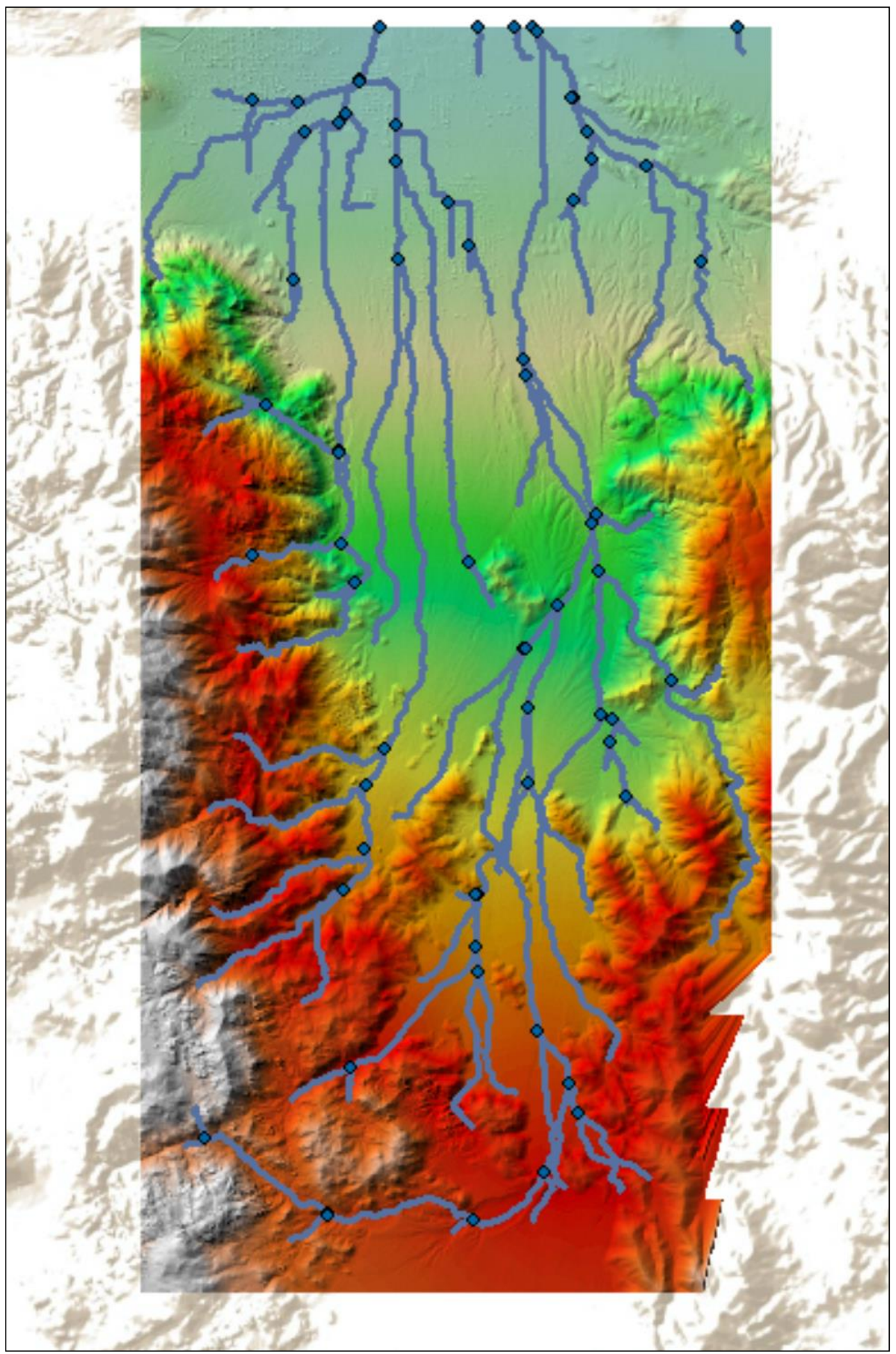

Figure 6-1: Drainage lines and drainage points from a 0.5m DEM. 




Figure 6-2: Drainage lines and drainage points from a 1m DEM. 


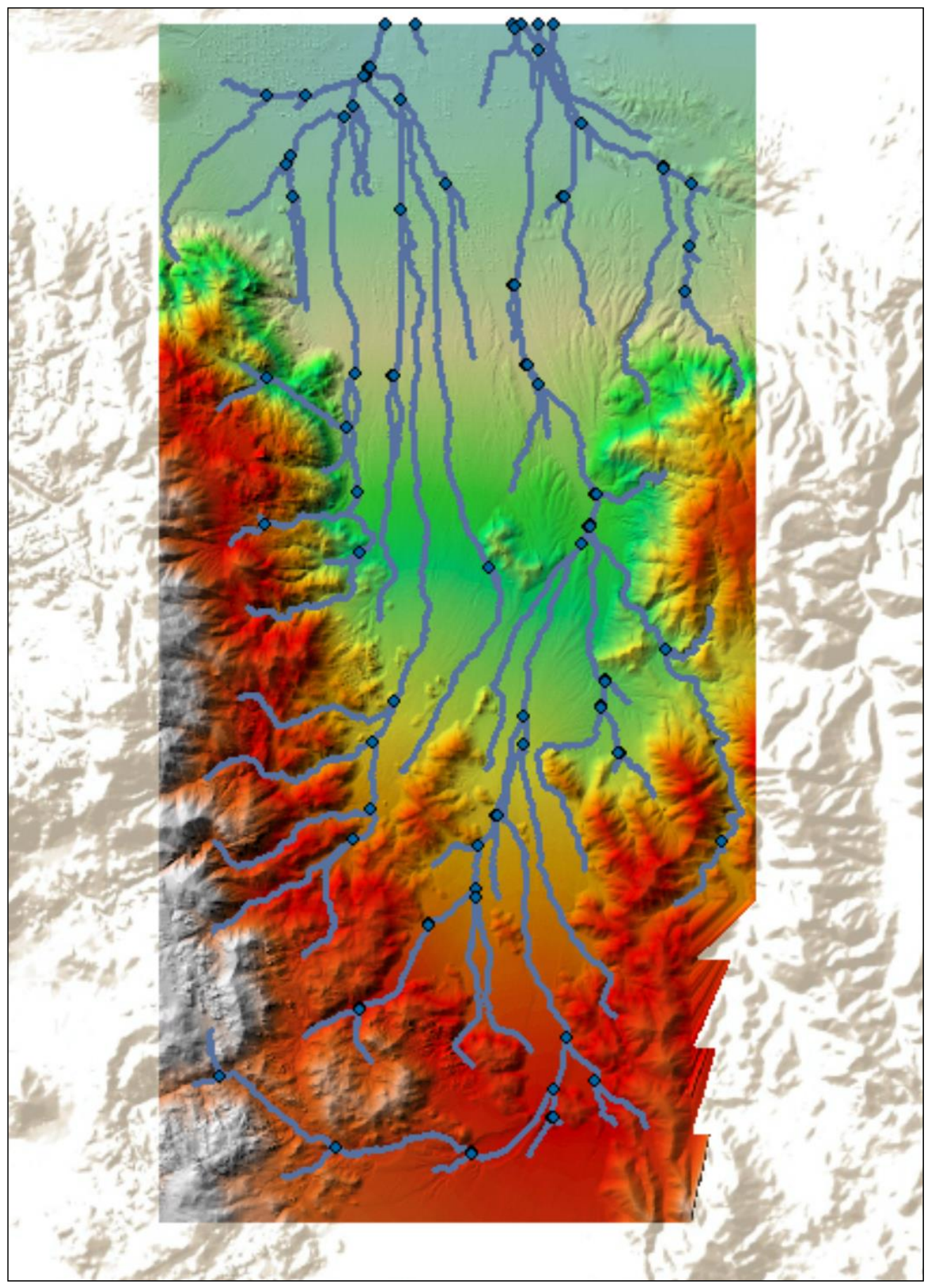

Figure 6-3: Drainage lines and drainage points from a $5 \mathrm{~m}$ DEM. 

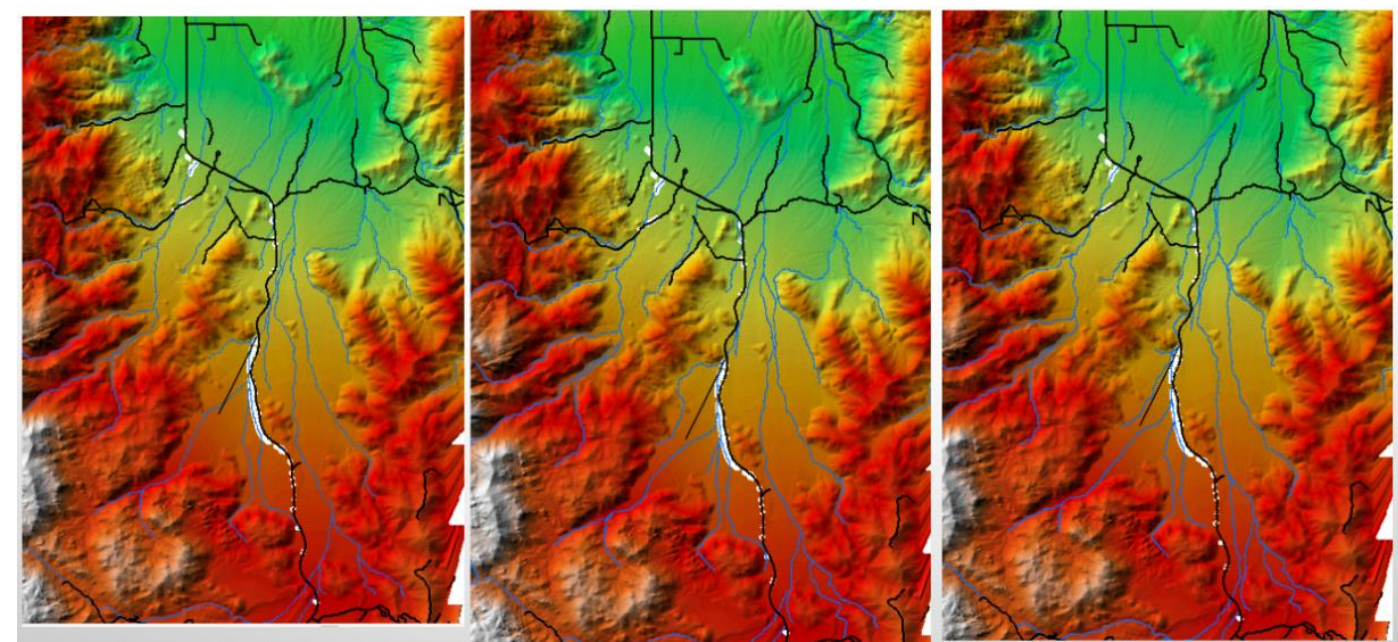

Drainage line $5 \mathrm{~m}$

Drainage line $0.5 \mathrm{~m}$

Figure 6-4: A figure comparing the output from different resolutions.

Despite the different resolutions used in terrain preprocessing and because of fill sinks procedure used to create the input Hydro DEMs used, and as expected, there was not much noticeable difference in output results, such as the number, shape and locations of streamlines generated. As such, the results from the $0.5 \mathrm{~m}$ DEM was adopted for further analysis on the efficiency of water diversion berms. The following figure shows some noticeable differences at a large scale for a similar location on all the three DEMs. 


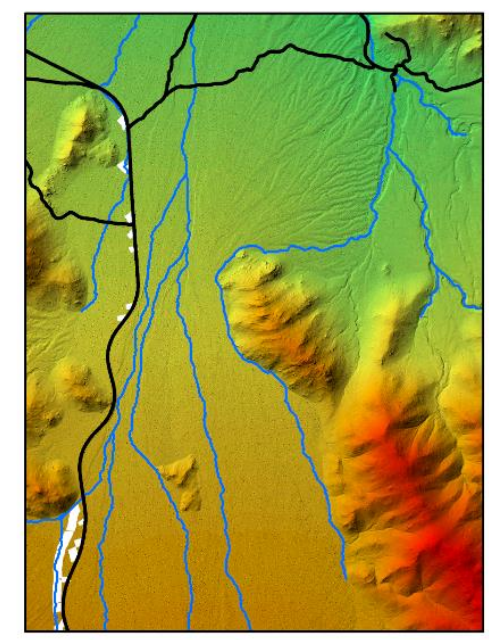

$0.5 \mathrm{~m}$ DEM

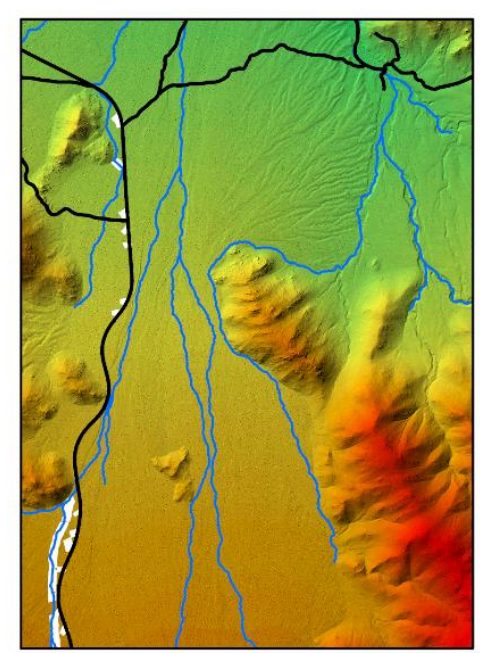

$1 \mathrm{~m}$ DEM

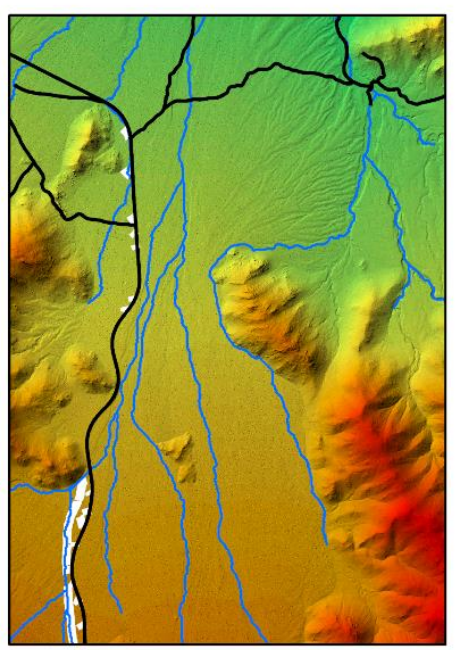

$5 m$ DEM

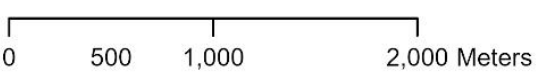

Figure 6-5: Noticeable differences from different resolutions at a larger scale

A further analysis on drainage points and drainage lines produced from the different resolutions used showed that a $0.5 \mathrm{~m}$ DEM produced 119 drainage lines and drainage points, $1 \mathrm{~m}$ DEM produced 135 while $5 \mathrm{~m}$ DEM had 128. The number of drainage lines were equal to the number of drainage points.

\subsection{Efficiency of Water Diversion Berms}

The diversion berms feature layer provided by the client contained a total of 112 features all located in the southern end of the study area. They are supposed to slow down the water velocity in the stream channels that cross the road. Considerations in determining the efficiency of these diversion berms was determined by their location in relation to the stream channels and whether their location influenced the flow direction of the channel that they were located along. The success criteria for the water diversion berms was that berms needed to be placed in a stream channel in such a way that it influenced the way the channel flowed for that stream. The failure criteria were that a berm either allowed the stream to pass through it indicating that it was damaged and needed repair or was not placed correctly, thus allowing the stream to flow behind the berm.

Figure 6-6 shows the location of all the water diversion berms in the study area for this project in relation to Park Blvd. 


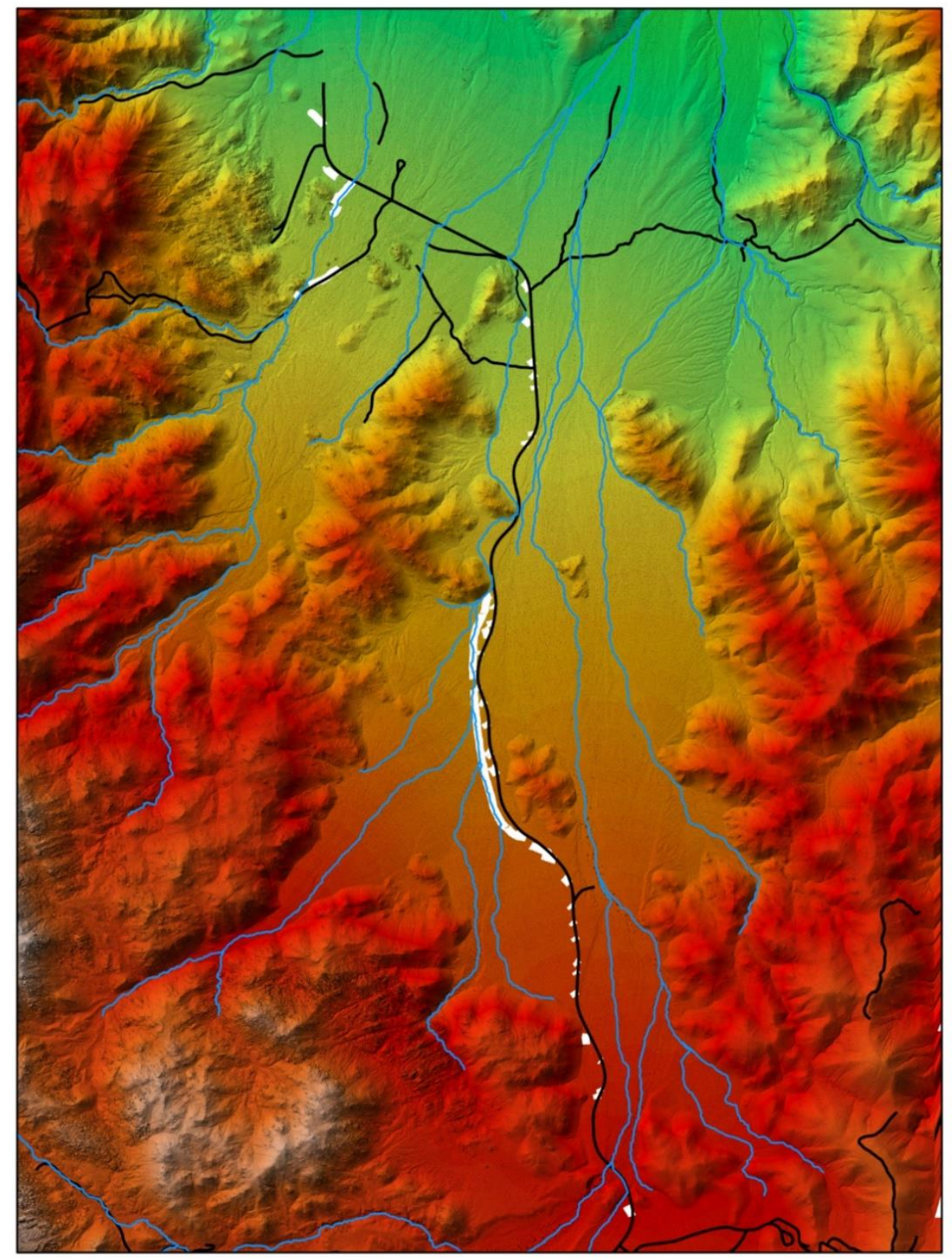

DrainageLine

Roads

Diversion_Berms

Figure 6-6: Diversion berms, major roads and stream channels

Generally, the middle section of the diversion water berms was efficient in the way it altered the general flow of stream channels when the size of the watershed was considered. This led to the creation of an empty watershed in the middle that had no streams flowing into it from the watershed. The following Figure 6-7 shows the watersheds, streams, roads, and diversion berms. 


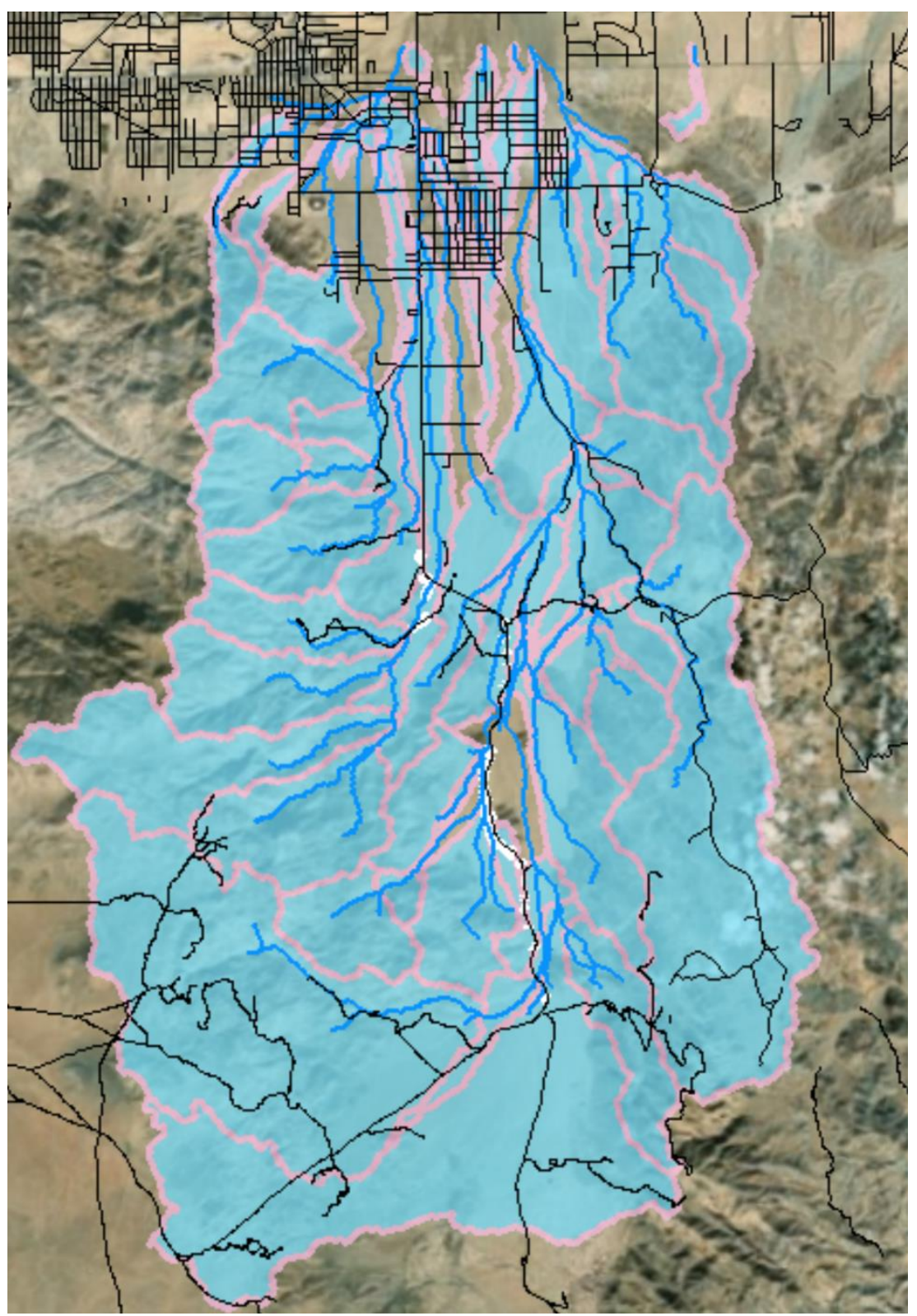

Figure 6-7: Influence of water diversion berms on a watershed drainage line.

A closer look at the water diversion in the middle section revealed that it was successful in controlling the stream channels from the surrounding watersheds. These streams converged at one point where they eventually crossed the road. 


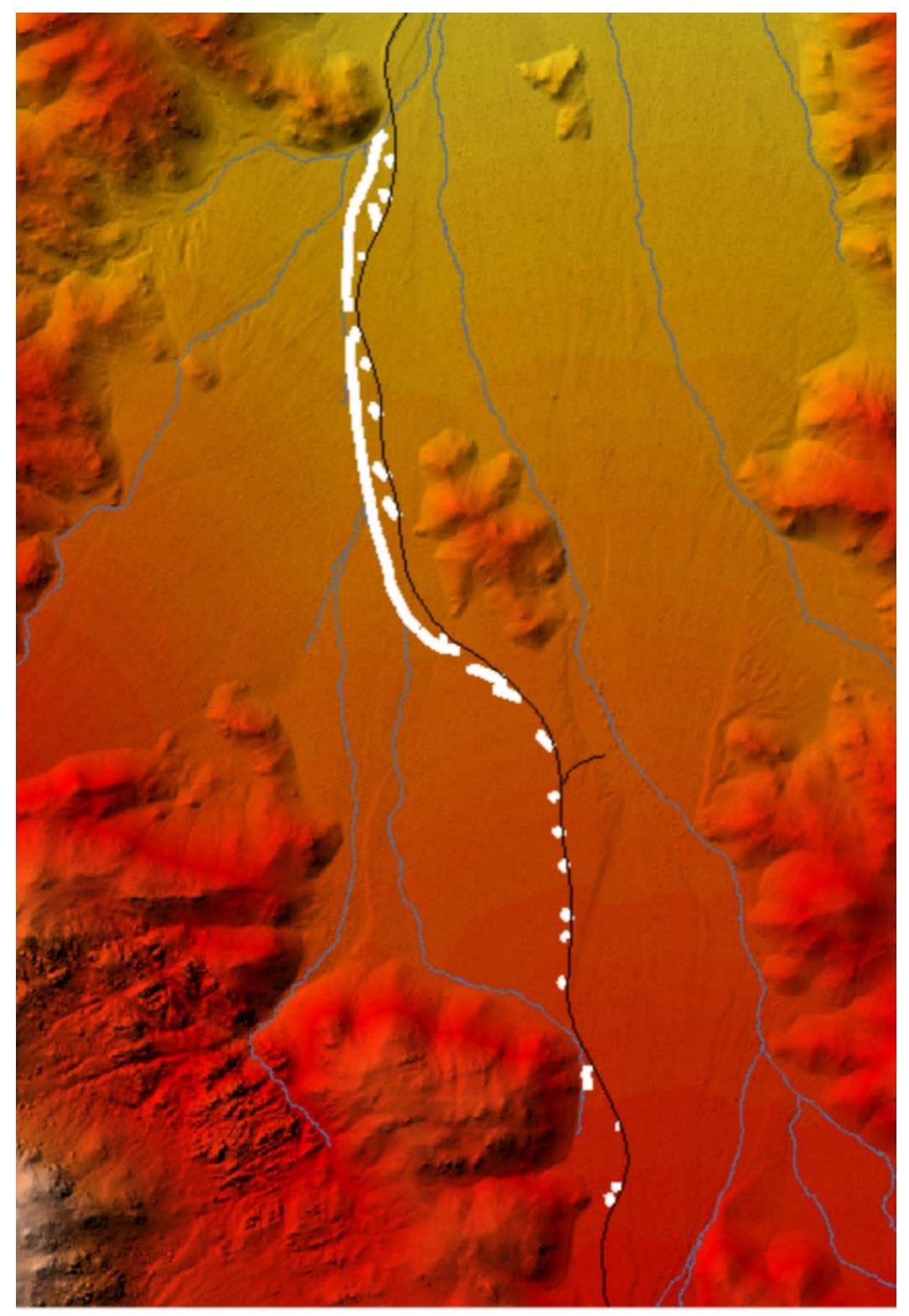

Figure 6-8: An effective water diversion berm.

The sections in Figure 6-8 of water berms were considered to be efficient in protecting the road from water destruction. However, since the streams were converging at a single point, the discharge was higher and thus further interventions were needed at that section. This study proposed a water holding dam at the section where all the streams were converging to further reduce the impact on the road section. To understand the dam specifications, it was important to understand the discharge amount and precipitation at that particular section.

Using the USGS StreamStats web app, point delineation was done at the convergence point. Figure 6-9 shows the watershed at the convergence point. 


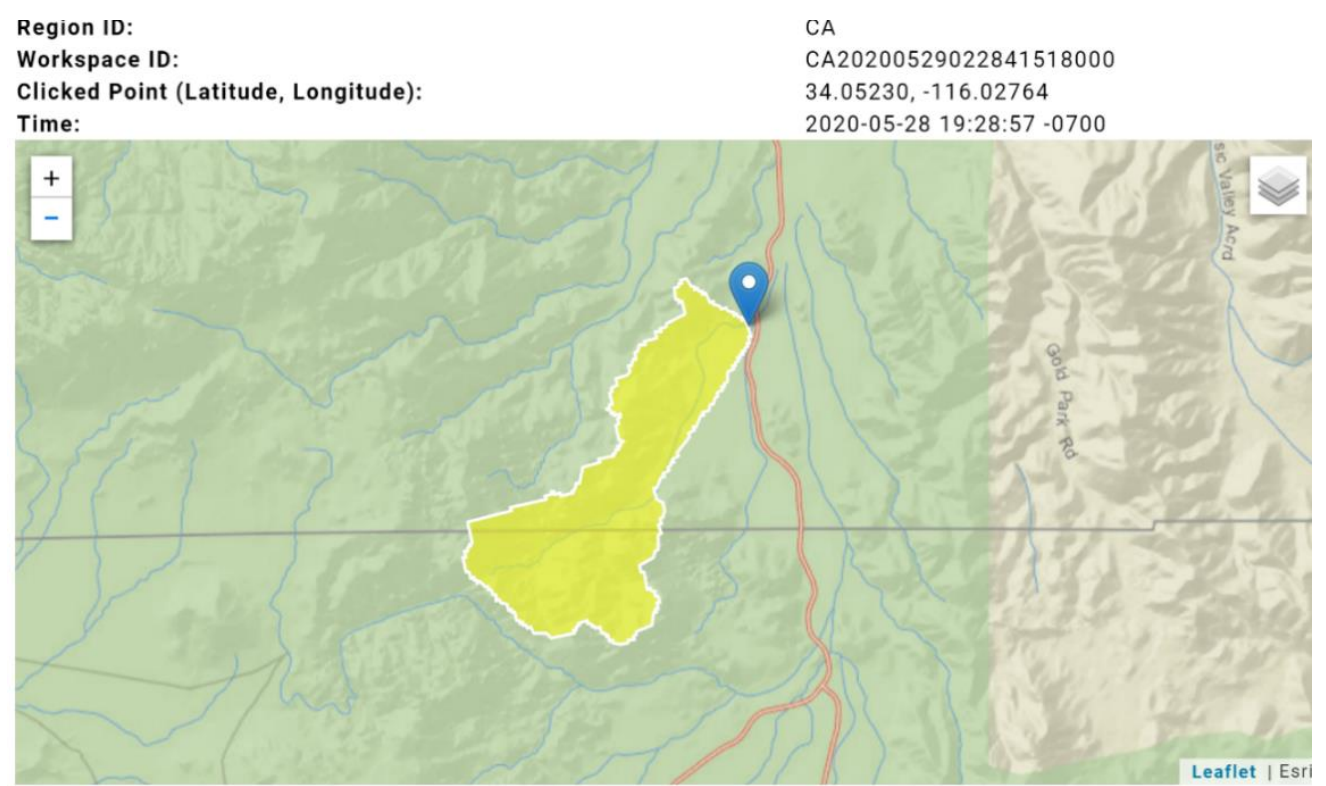

Figure 6-9: StreamStats point delineation. 


\begin{tabular}{llll} 
Parameter Code & Parameter Description & Value & Unit \\
\hline DRNAREA & Area that drains to a point on a stream & 1.9 & square miles \\
& &
\end{tabular}

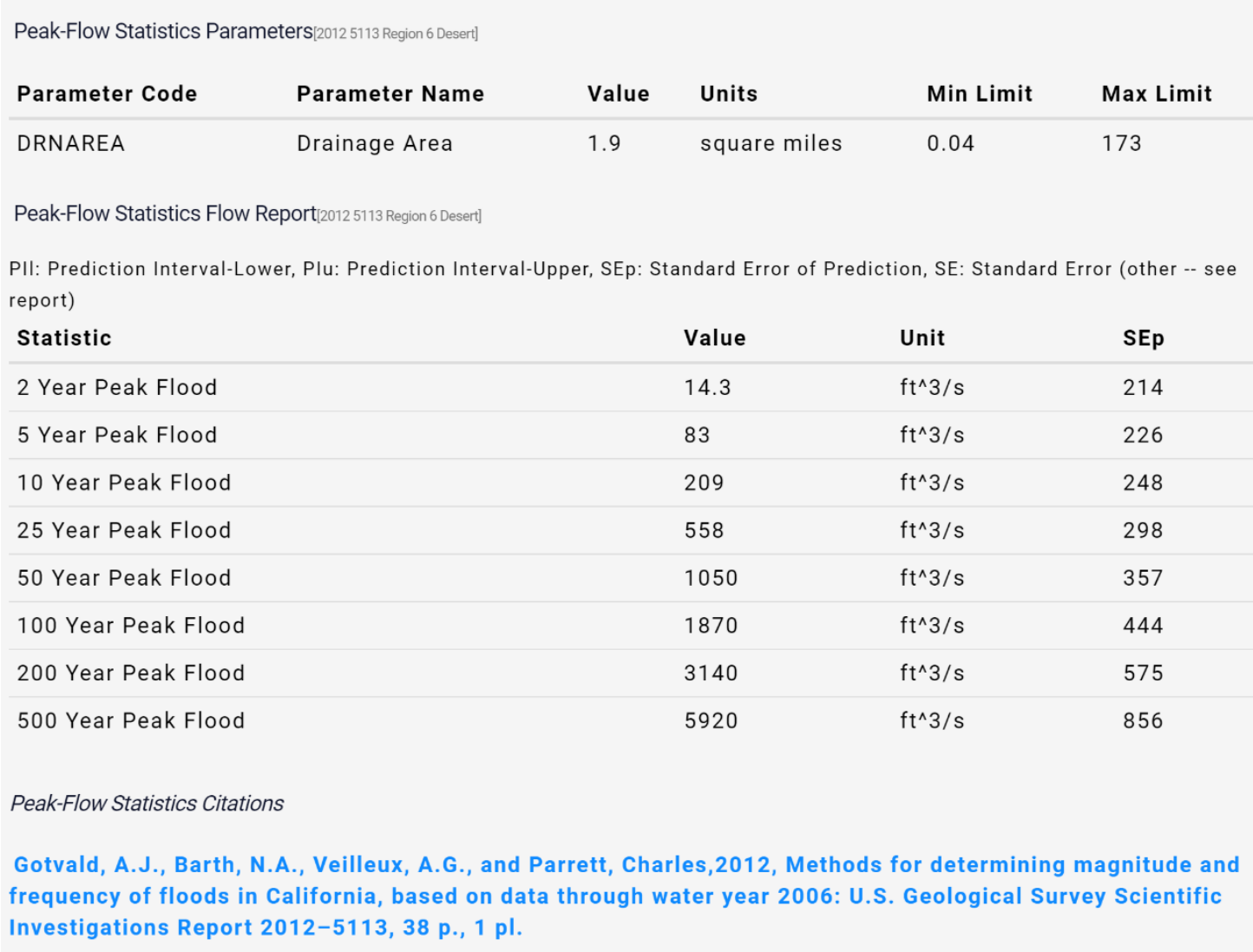

\section{Figure 6-10: StreamStats report}

It was possible to estimate the height of water diversion berm for the section based on a 24-hr peak discharge derived from StreamStats report for a 5-year peak period.

$$
Q=\vee A=\left(\frac{1 \cdot 49}{n}\right) A R \sqrt[2 / 3]{s}
$$

A $=$ Width * Height

Where:

$\mathrm{Q}=$ The flow rate in $\mathrm{ft}^{3} / \mathrm{s}$

$\mathrm{V}=$ Velocity in $\mathrm{ft} / \mathrm{s}$

$\mathrm{A}=$ Flow area in $\mathrm{ft}^{2}$

$\mathrm{n}=$ Manning's roughness coefficient

$\mathrm{R}=$ Hydraulic radius in $\mathrm{ft}$

$\mathrm{S}=$ Channel slope

Using StreamStats, a 5-year peak discharge for the point was found to be $80 \mathrm{ft}^{3} / \mathrm{s}$ and the slope for the area was found to be approximately 5 percent. A 5-year peak period was 
chosen because the diversion berms are repaired after about 5 years and a peak discharge of 5 years is likely to cause damages to the water diversion berms during that period.

Using an online normal depth calculator provided by National Weather Service (NWS), for calculating depth and width for a uniform flow accessible via web URL https://www.weather.gov/aprfc/NormalDepthCalc, the water diversion berm height could be estimated. The calculator takes into consideration the slope of the area, water flow in $\mathrm{ft}^{3} / \mathrm{s}$ and Manning's roughness coefficient which is between 0.023 and 0.035 for barren areas and desert pavements. Figure 6-11 shows the flow discharge for a stream.

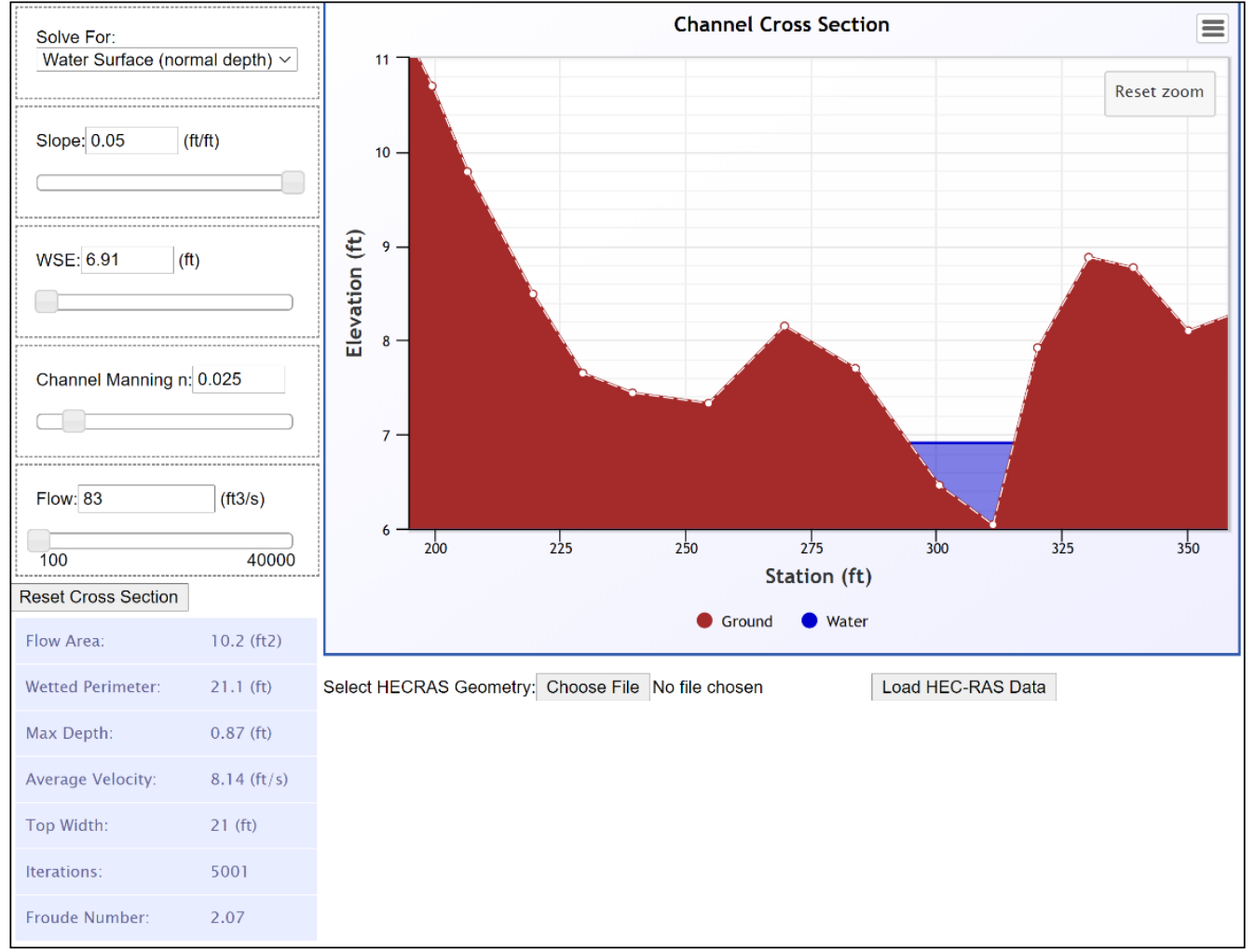

Figure 6-11: Normal depth calculator by NWS.

Based on the results from the normal depth calculator provided by NWS, it is possible to estimate the height of water diversion berms as $1 \mathrm{ft}$ based on a 5-year peak discharge from Figure 6-11.

To estimate the size of a temporary water dam required to hold the runoff, using drainage area characterization for the watershed in Figure-6-9 as the input shapefile. Using slice increments of $0.5 \mathrm{~m}$, a table was generated that shows potential water volume that can be stored based on the height of the dam. 


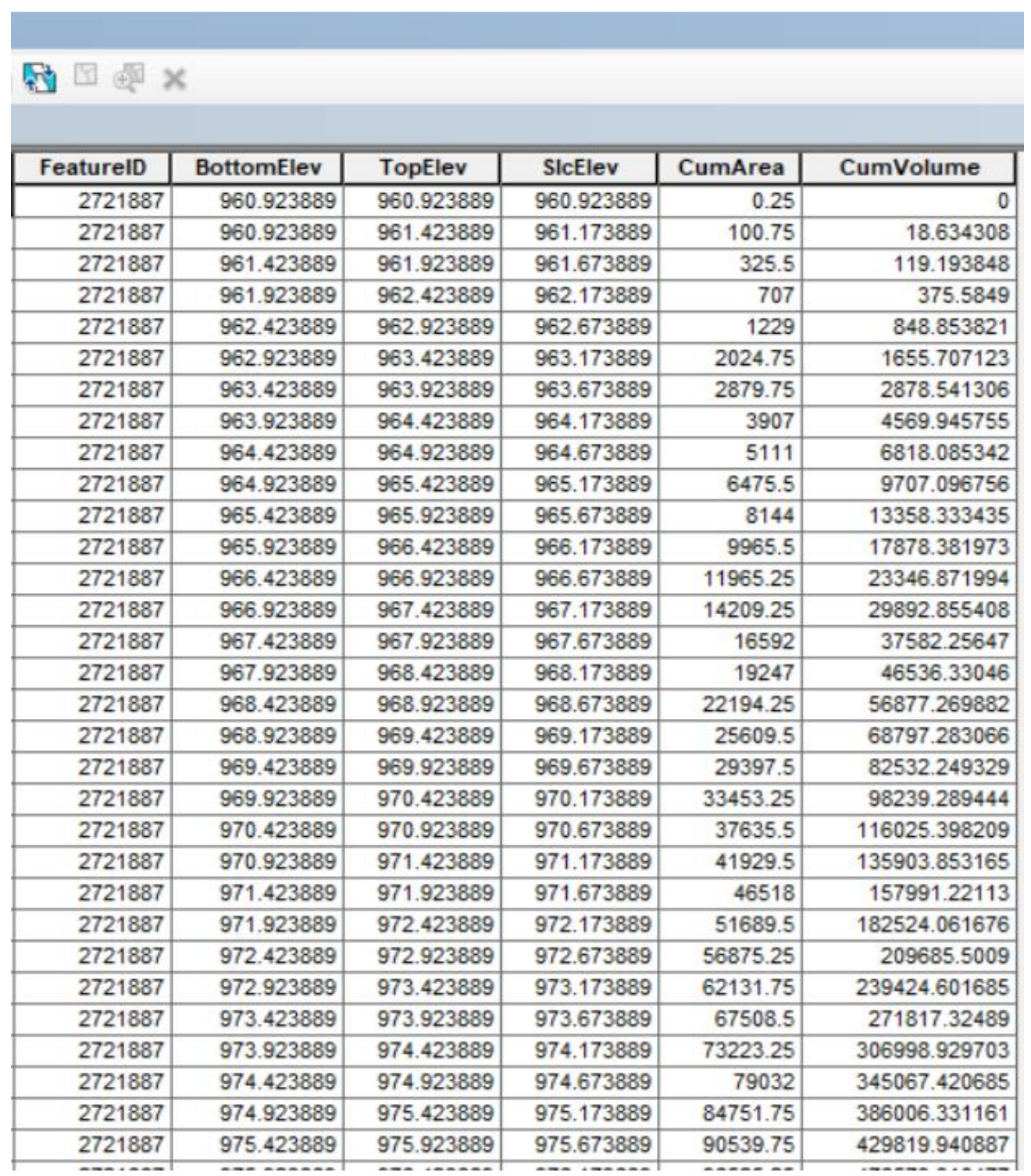

Figure 6-12: Drainage Area Characterization table

To get the dam dimensions, precipitation data from NOAA Atlas 14 web portal application that provides point precipitation frequency estimate in the US.

https://hdsc.nws.noaa.gov/hdsc/pfds/pfds_map_cont.html?bkmrk=ca was used to get point estimate precipitation for the watershed area in the park. The precipitation data ranges from 1-year period to 1000-years period. 


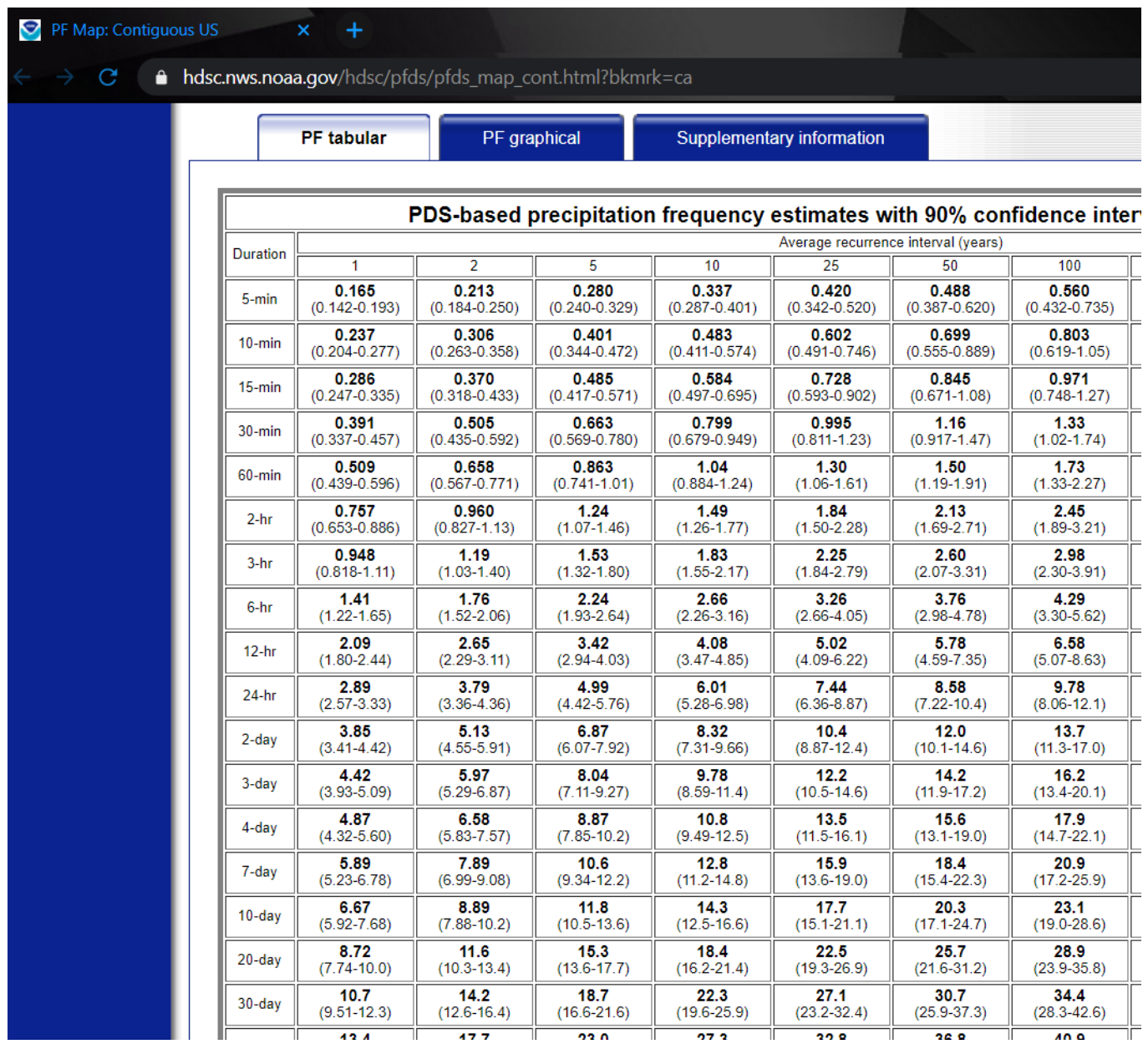

Figure 6-13: Point precipitation estimate for the area from NOAA Atlas 14

To derive water volume, precipitation data from NOAA Atlas table for a 5-year and 2-year precipitation estimate period with durations of 5-minutes, 12 hours and 24 hours were converted to meters multiplied by watershed area derived from drainage area characterization to provide dam capacity. This provided a reference table used compare duration of precipitation different dam heights can hold based on total precipitation received in the watershed. 


\begin{tabular}{|c|c|c|c|c|c|c|}
\hline Cumulative Volume & Range for 5 year rain & Range for 2 year Rain & & & & \\
\hline 0 & 0 & & & \multicolumn{2}{|c|}{ Volume reference table } & \\
\hline 18.63430786 & 0.5 & & & & & \\
\hline 119.1938477 & 1 & & Duration for 5-year & Volume(m3) & 2-Years & Volume \\
\hline 375.5848999 & 1.5 & & $5 \mathrm{~min}$ & \multicolumn{2}{|c|}{$50087.579535 \mathrm{~min}$} & 35366.49881 \\
\hline 848.8538208 & 2 & & $30 \mathrm{~min}$ & \multicolumn{2}{|c|}{$126206.338430 \mathrm{~min}$} & 89044.58583 \\
\hline 1655.707123 & 2.5 & & 1 HRS & \multicolumn{2}{|c|}{ 157982.3297 1 HRS } & 111485.2577 \\
\hline 2878.541306 & 3 & & 6 HRS & \multicolumn{2}{|c|}{249540.27086 HRS } & 179525.3747 \\
\hline 4569.945755 & 3.5 & & $12 \mathrm{HRS}$ & \multicolumn{2}{|c|}{299807.3757 12 HRS } & 215430.4496 \\
\hline 6818.085342 & 4 & & 24 HRS & \multicolumn{2}{|c|}{375208.03324 HRS } & 262107.047 \\
\hline 9707.096756 & 4.5 & & & & & 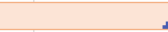 \\
\hline 13358.33344 & 5 & & & & & \\
\hline 17878.38197 & 5.5 & & & \multicolumn{3}{|c|}{ Precipitation table for 5-year and 2-year } \\
\hline 23346.87199 & 6 & & 5-year period & \multirow{2}{*}{\multicolumn{2}{|c|}{ - rain(Inches) - 2 -year }} & " Rain(Inches)|" \\
\hline 29892.85541 & 6.5 & & $5 \mathrm{~min}$ & \multirow{2}{*}{\multicolumn{2}{|c|}{$\begin{array}{c}0.2795 \mathrm{~min} \\
1.69 \quad 12 \mathrm{HRS}\end{array}$}} & 0.197 \\
\hline 37582.25647 & 7 & $5 \mathrm{Min}$ & 12HRS & & & 1.2 \\
\hline 46536.33046 & 7.5 & & 24HRS & \multicolumn{2}{|c|}{$2.0924 \mathrm{HRS}$} & 1.46 \\
\hline 56877.26988 & 8 & & $1 \mathrm{HR}$ & \multicolumn{2}{|c|}{$0.881 \mathrm{HR}$} & 0.621 \\
\hline 68797.28307 & $8.55 \mathrm{Min}$ & & 6 HRS & \multicolumn{2}{|c|}{$1.396 \mathrm{HRS}$} & 1 \\
\hline 82532.24933 & 9 & & $30 \mathrm{~min}:$ & \multirow{2}{*}{\multicolumn{2}{|c|}{$0.70930 \mathrm{~min}:$}} & 0.496 \\
\hline 98239.28944 & 9.5 & 30 Min & & & & \\
\hline 116025.3982 & 10 & $1 \mathrm{HR}$ & & & & \\
\hline 135903.8532 & 10.530 Min & & Total Watershed Are & ea: $7067914 \mathrm{~m} 2$ & & \\
\hline 157991.2211 & $111 \mathrm{HR}$ & & & & & \\
\hline 182524.0617 & 11.5 & $6 \mathrm{HRS}$ & & & & \\
\hline 209685.5009 & 12 & & & & & \\
\hline
\end{tabular}

Figure 6-14: Dam capture capacity for different heights based on precipitation

Using a dam height of $11.5 \mathrm{~m}$, a flood extent for the watershed was generated to show the area covered by the dam in regard to the area in the watershed. 


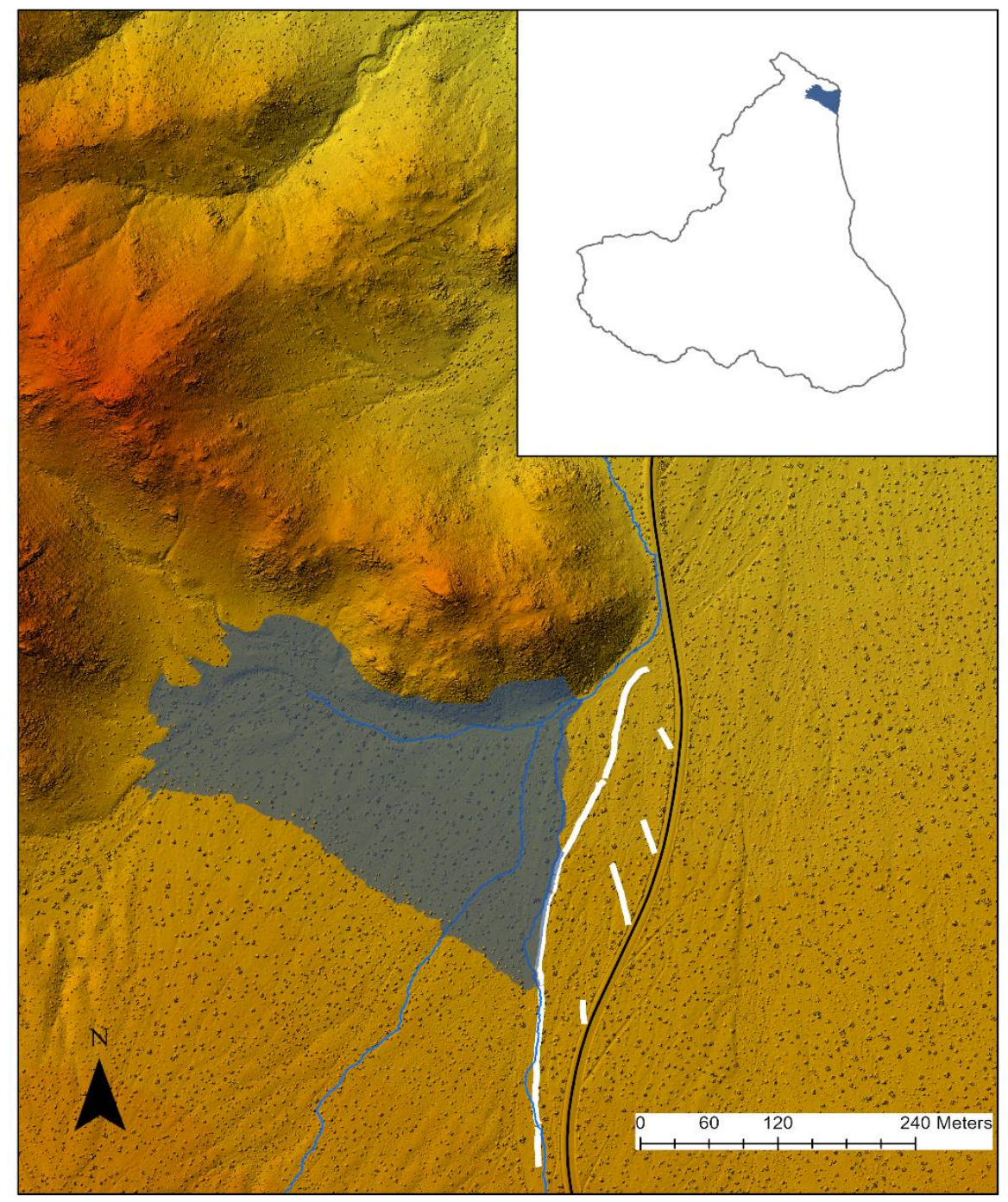

Figure 6-15: Location of the Dam in the watershed

\subsection{Areas that Need Additional Water Diversion Berms}

From the analysis, there were areas that could use additional diversion berms. Figure 616 shows a section of a stream that crosses the Park Blvd road without any intervention at the section marked X. 


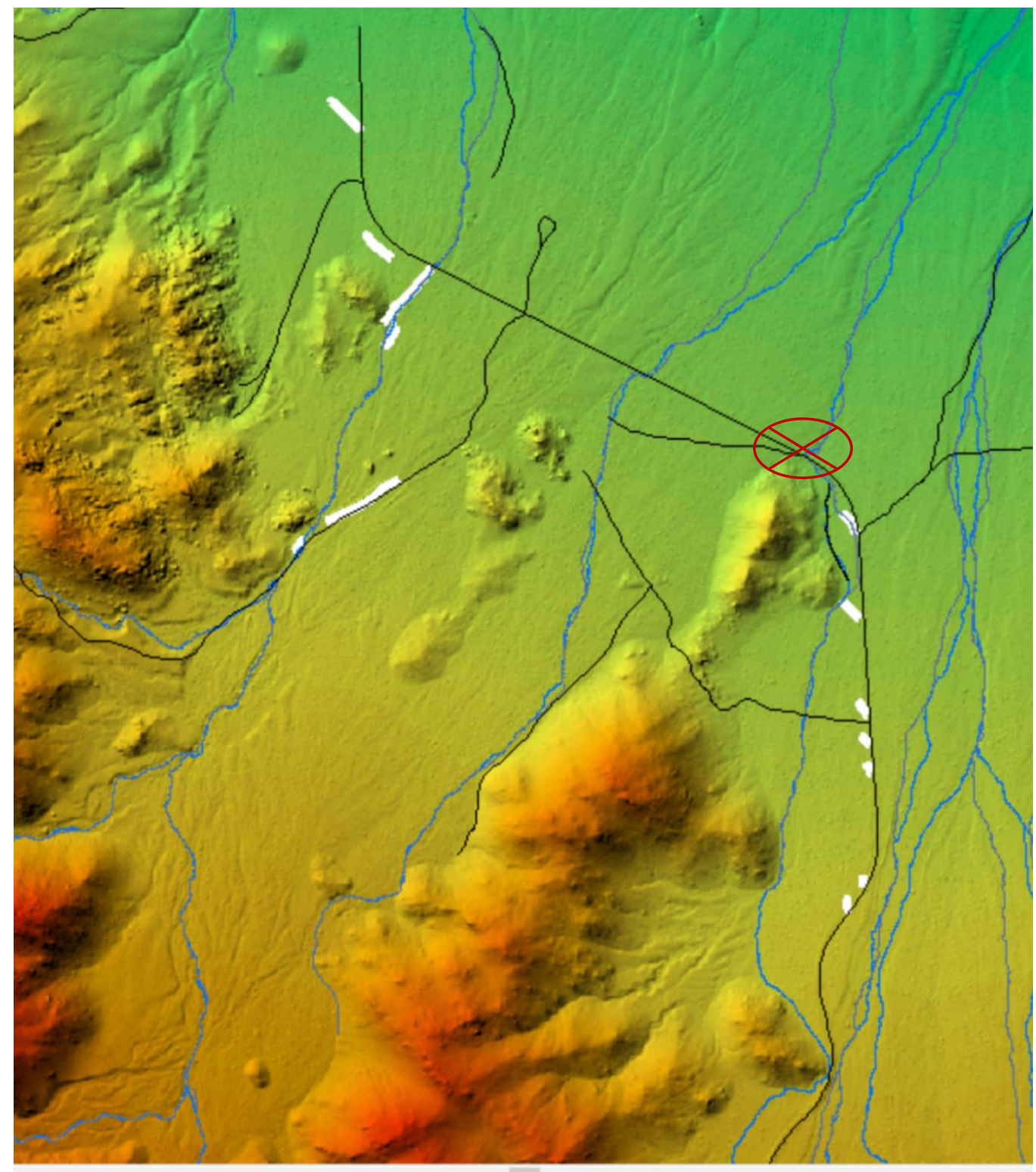

Figure 6-16: A section that needs additional berms.

Using StreamStats point delineation, a report was generated to estimate the area for the watershed and water discharge at a section just before the stream crosses the road. Figure 6-17 shows a section of StreamStats report on the shape of watershed at the point marked $\mathrm{X}$ before the road for the stream. 


\section{StreamStats Report additional berms}

Region ID:

Workspace ID:

CA

Clicked Point (Latitude, Longitude):

CA20200608182905566000

$34.07076,-116.02992$

Time:

2020-06-08 11:29:21-0700

$+$

Figure 6-17: Point delineation for a selected stream without water berms.

As shown from Figure 6-17, the watershed potentially goes beyond the study area, and as such, nearby streams flow from the mountains into the park, across Park Blvd road, down into the urbanized areas. This long flow length and large watershed can potentially lead to a large discharge crossing the road, leading to high risk of damage to the road. It was critical to understand the flow statistics magnitude in terms of water discharge at the point where the stream and Park Blvd road intersected.

Figure 6-18 is a flow statistic for peak discharge and the area size of the watershed. 


\begin{tabular}{llll} 
Parameter Code & Parameter Description & Value & Unit \\
\hline DRNAREA & Area that drains to a point on a stream & 1.9 & square miles \\
& &
\end{tabular}

\begin{tabular}{|c|c|c|c|c|c|}
\hline Parameter Code & Parameter Name & Value & Units & Min Limit & Max Limit \\
\hline DRNAREA & Drainage Area & 1.9 & square miles & 0.04 & 173 \\
\hline \multicolumn{6}{|c|}{ Peak-Flow Statistics Flow Report[20125113 Region 6 Desert] } \\
\hline \multicolumn{6}{|c|}{$\begin{array}{l}\text { PII: Prediction Interval-Lower, Plu: Prediction Interval-Upper, SEp: Standard Error of Prediction, SE: Standard Error (other -- se } \\
\text { report) }\end{array}$} \\
\hline Statistic & & & Value & Unit & SEp \\
\hline 2 Year Peak Flood & & & 14.3 & $\mathrm{ft}^{\wedge} 3 / \mathrm{s}$ & 214 \\
\hline 5 Year Peak Flood & & & 83 & $\mathrm{ft}^{\wedge} 3 / \mathrm{s}$ & 226 \\
\hline 10 Year Peak Flood & & & 209 & $\mathrm{ft}^{\wedge} 3 / \mathrm{s}$ & 248 \\
\hline 25 Year Peak Flood & & & 558 & $\mathrm{ft}^{\wedge} 3 / \mathrm{s}$ & 298 \\
\hline 50 Year Peak Flood & & & 1050 & $\mathrm{ft}^{\wedge} 3 / \mathrm{s}$ & 357 \\
\hline 100 Year Peak Flood & & & 1870 & $\mathrm{ft}^{\wedge} 3 / \mathrm{s}$ & 444 \\
\hline 200 Year Peak Flood & & & 3140 & $\mathrm{ft}^{\wedge} 3 / \mathrm{s}$ & 575 \\
\hline 500 Year Peak Flood & & & 5920 & $\mathrm{ft}^{\wedge} 3 / \mathrm{s}$ & 856 \\
\hline
\end{tabular}

Gotvald, A.J., Barth, N.A., Veilleux, A.G., and Parrett, Charles,2012, Methods for determining magnitude and frequency of floods in California, based on data through water year 2006: U.S. Geological Survey Scientific Investigations Report 2012-5113, 38 p., 1 pl.

\section{Figure 6-18: Flow statistics from StreamStats}

As shown in Figure 6-18, the water discharge at the section where the stream crosses the Park Blvd road was found to be $83 \mathrm{ft}^{3} / \mathrm{s}$ for a 5 - year peak flood discharge. 


\section{Chapter 7 - Conclusions and Future Work}

\subsection{Project Conclusion}

The purpose of this project was to determine the efficiency of existing water diversion berms in Joshua Tree National Park (JTNP) North entrance, provide recommendations on where new ones should be built and areas that need to be reinforced. This analysis was meant to protect roads that are at risk of flash floods, specifically the Park Blvd road in the Northern entrance. To accomplish the purposes of this project, a GIS software specifically ArcGIS was chosen to address the geographic nature of this problem.

Arc Hydro tools were ideal because of the diverse functionalities they offer in solving hydrological and terrain problems. These tools were used in generating elevation surfaces and delineating watersheds. These watersheds were based on three separate DEM resolutions for accuracy purposes especially stream locations and drainage points. This was also useful in understanding the watersheds that directly contribute to the streams that intersect the roads especially the Park Blvd road.

To actualize the project, there was a need to understand the stream peak discharge for the streams of interest which was useful in understanding how much water discharge were in the streams that crossed the road that the project focused on. This was achieved by using the stream discharge data from StreamStats web app.

To determine the efficiency of water diversion features, the criteria used was the influence of the water berm on the general drainage pattern of the streams and whether there are water berms that have streams running through them.

The project further made recommendations on establishing a dam where the stream converged before crossing the road. This would be ideal in holding off the excess water and debris carried by the stream and consequently slowing down the stream velocity and therefore reducing the impact these have on the roads. Additionally, given the challenges encountered with metadata on diversion berms data, this project recommends adding an additional column on when each berm was last repaired.

\subsection{Future Work}

Much of this project was an engineering problem. One common source of berm destruction was due to erosion caused by water and debris in the stream channels. A comprehensive hydrological modelling that combines both ground and underground water flow can be done for the area that combines the discharge and erosion rate to determine such areas and consequently construct water diversion berms that are appropriate based on these two factors. This will also be critical in determining the individual berm construction specifications.

A second feasible project is in relation to the DEM resolution. The StreamStats web app delineation data and stream discharge estimation are based on a 30m DEM. There's room for more studies to be done on what DEM resolution can produce accurate stream delineation. One of the reasons why several DEM resolutions were used in delineation was trying to find the appropriate stream locations. 
A third feasible project is to carry out a comprehensive work on potential effects caused by using DEMs of different resolutions in delineation. Different DEM resolutions produced streams that have slightly different lengths and flow directions from each other.

The DEMs generated from this project were generated using average cell assignment type. More studies can be done using different cell assignment options such as minimums, maximum and nearest when converting LiDAR dataset to DEMs and the impact different cell assignments have in watershed delineation. 



\section{Works Cited}

Akan, O. A. (1993). Urban Stormwater Hydrology: A Guide to Engineering Calculations (p. 105). Switzerland: Taylor \& Francis. Retrieved July 07, 2020, from https://www.google.com/books/edition/Urban_Stormwater_Hydrology/ZyJtRojk $\mathrm{Dg} 0 \mathrm{C} ? \mathrm{hl}=\mathrm{en} \& \mathrm{gbpv}=1$

Angulo-Jaramillo, R., Bagarello, V., Iovino, M., \& Lassabatere, L. (2016). Infiltration measurements for soil hydraulic characterization (pp. 24-25). Switzerland: Springer. Retrieved July 08, 2020, from https://www.google.com/books/edition/Infiltration_Measurements_for_Soil_Hydr a/zYWQDAAAQBAJ?hl=en\&gbpv=1

Bowers, J. E. (1999). Flowers and Shrubs of the Mojave Desert. Tucson, Arizona: Southwest Parks and Monuments Association. Retrieved July 07, 2020, from https://www.google.com/books/edition/Flowers_and_Shrubs_of_the_Mojave_Des ert/3JhRR9Nlsh0C?hl=en\&gbpv=1

Chambers, C., \& Lapthorn, N. (2008). Deserts (p. 7). Chicago, IL: Heinemann. Retrieved July 6, 2020, from https://books.google.com/books?id=P-Co6hmk-

W8C\&printsec $=$ frontcover\&source $=g b s \_g e \_s u m m a r y \_r \& c a d=0 \# v=0$ epage $\& q \&$ $\mathrm{f}=$ false

Deodhar, M. J. (2009). Elementary engineering hydrology (pp. 99-100). New Delhi: Pearson Education. Retrieved July 07, 2020, from https://books.google.com/books?id=qFRezTsaxo8C $\&$ printsec=frontcover $\&$ source =gbs_ge_summary_r\&cad $=0 \# \mathrm{v}=$ onepage $\& \mathrm{q} \& \mathrm{f}=$ false

El Bastawesy, M., White, K. and Nasr, A. (2009). Integration of remote sensing and GIS for modelling flash floods in Wadi Hudain catchment, Egypt. Hydrol. Process., 23: 1359-1368. https://doi.org/10.1002/hyp.7259

Eyelade, O. (2012). Net Zero Water Study for Fort Irwin California (Master's thesis, University of Redlands). Retrieved April 27, 2020, from https://inspire.redlands.edu/gis_gradproj/3

Gotvald, A.J., Barth, N.A., Veilleux, A.G., \& Parrett C. (2012). Methods for determining magnitude and frequency of floods in California, based on data through water year 2006: U.S. Geological Survey Scientific Investigations Report 2012-5113. Retrieved April 27, 2020, from https://pubs.usgs.gov/sir/2012/5113/pdf/sir2012-5113.pdf

Lennox, D. (2007). In Now You Know Extreme Weather (p. 33). Ontario, Canada:

Dundurn. Retrieved July 09, 2020, from https://books.google.com/books?id=PFJEV7DUjs0C\&printsec=frontcover\&sourc $\mathrm{e}=\mathrm{gbs} \_\mathrm{ge} \_$summary_r\&cad $=0 \# \mathrm{v}=$ onepage $\& \mathrm{q} \& \mathrm{f}=$ false

Lines, G. C. (1996). Groundwater and Surface-water Relations Along the Mojave River, Southern California. (pp. 1-3). U.S Geological Survey, Water Resources Investigation Report 95 -4189: Earth Science Information Center. Retrieved July 07, 2020, from https://books.google.com/books?id=ZDzqhN5ZkKEC\&printsec=frontcover\&sour $\mathrm{ce}=\mathrm{gbs} \_g e \_s u m m a r y \_r \& c a d=0 \# \mathrm{v}=$ onepage $\& \mathrm{q} \& \mathrm{f}=\mathrm{false}$ 
Lisk, M., \& Fox, W. L. (2005). Desert water (p. 53). Portland, Oregon. Graphic Arts Books. Retrieved July 06, 2020, from https://books.google.com/books?id=L2huBuA4THAC\&printsec=frontcover\&sour $\mathrm{ce}=\mathrm{gbs} \_\mathrm{ge} \_$summary_r$\& \mathrm{cad}=0 \# \mathrm{v}=$ onepage $\& \mathrm{q} \& \mathrm{f}=$ false

Maidment, D. R., \& Djokic, D. (2000). Hydrologic and hydraulic modeling support with geographic information systems (p. 197). Redlands, CA: Environmental Systems Research Institute. Retrieved July 06, 2020, from https://www.google.com/books/edition/Hydrologic_and_Hydraulic_Modeling_Su ppor/A_iTo003UUAC?hl=en\&gbpv $=1$

Maskey, S. (2004). Modelling uncertainty in flood forecasting systems (Doctoral dissertation). Retrieved from Google Scholar database. (ISBN: 9781482284027)

Mays, L. W. (2019). Water Resources Engineering (p. 312). United Kingdom: Wiley. Retrieved July 07, 2020, from https://www.google.com/books/edition/Water_Resources_Engineering/3k6MDw AAQBAJ?hl=en\&gbpv=1

Mishra, S. K., \& Singh, V. P. (2011). Soil conservation service curve number (SCS-CN) methodology (p. 105). Dordrecht: Springer. Retrieved July 07, 2020, from https://www.google.com/books/edition/Soil_Conservation_Service_Curve_Numb er_S/DbXnCAAAQBAJ?hl=en\&gbpv=1

Mooney, H. A., \& Zavaleta, E. (2016). Ecosystems of California (p. 638). Oakland, CA: University of California Press. Retrieved July 08, 2020, from https://books.google.com/books?id=HkT_CgAAQBAJ\&printsec=frontcover\&sou rce=gbs_ge_summary_r\&cad $=0 \# \mathrm{v}=$ onepage $\& \mathrm{q} \& \mathrm{f}=$ false

Mullen, J.R., Hayes, P.O. \& Agajanian, J.A. (1993). Water resources data California. Water year 1993. U.S. Geological Survey Water-Data Report. California.

Retrieved July 07, 2020, from https://pubs.usgs.gov/wdr/1993/ca-93/WDR-1993-vol1.pdf

Parola, A. C., Kamojjala, S., Hagerty, D. J. (1998). Highway Infrastructure Damage Caused by the 1993 Upper Mississippi River Basin Flooding. Washington, DC. National Academies Press. Retrieved July 08, 2020, from http://onlinepubs.trb.org/onlinepubs/nchrp/nchrp_rpt_417.pdf

Seward, L. L. (2017). Flooding Disasters Cost Billions in 2016. Retrieved July 08, 2020, from https://www.pewtrusts.org/en/research-andanalysis/articles/2017/02/01/flooding-disasters-cost-billions-in-2016

Tung, Y., \& Mays, L. W. (2002). Hydrosystems Engineering and Management (p. 423). United States: Water Resources Publications. Retrieved July 07, 2020, from https://www.google.com/books/edition/Hydrosystems_Engineering_and_Manage ment/J2eszxVKL-EC?hl=en\&gbpv=1

Walesh, S. G. (1991). Urban surface water management (p. 97). New York: John Wiley \& Sons. Retrieved July 07, 2020, from https://books.google.com/books?id=LcZUPtDykQC\&printsec=frontcover\&source=gbs_ge_summary_r\&cad $=0 \# \mathrm{v}=\mathrm{on}$ epage \&q\&f=false

Walker, L. R., \& Landau, F. H. (2018). A natural history of the Mojave Desert (pp. 48264). Tucson: The University of Arizona Press. Retrieved July 07, 2020, from 
https://books.google.com/books?id=s8FIDwAAQBAJ\&newbks=0\&printsec=fron tcover $\& \mathrm{hl}=\mathrm{en} \# \mathrm{v}=$ onepage $\& \mathrm{q} \& \mathrm{f}=$ false

Ward, A. D., Trimble, S. W., Burckhard, S. R., \& Lyon, J. G. (2016). Environmental hydrology (p. 193). Boca Raton, FL: CRC Press, Taylor \& Francis Group. Retrieved July 07, 2020, from https://www.google.com/books/edition/Environmental_Hydrology/QgaQCgAAQ BAJ?hl=en\&gbpv $=1$ 



\section{Appendix A. Project Model}

A terrain Preprocessing Model

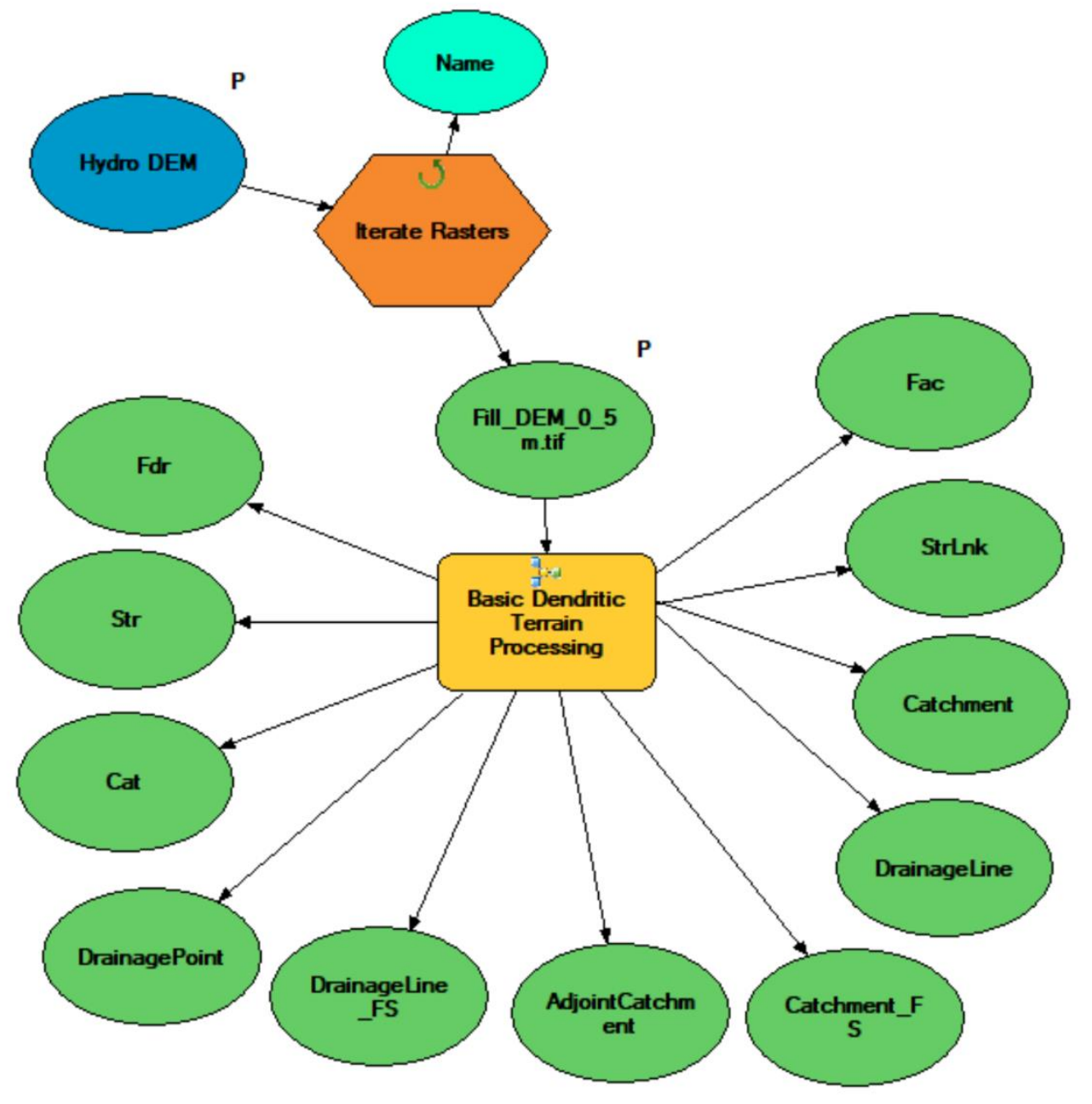




\section{Appendix B. FLOWSTATS Report}

A FLOWSTATS attribute table for a 5-year peak flood for 119 stream points

\begin{tabular}{|c|c|c|c|c|c|c|c|c|}
\hline JBJECTID & Name & RegionID & RegionName & AreaPercent & AreaSqMi & Statlabel & StatName & Value \\
\hline 2 & 1 & gc1534 & 2012_5113_Region_6_... & 100 & 0.05 & PK5 & 5 Year Peak Flood & 13.2 \\
\hline 10 & 2 & gc1534 & 2012_5113_Region_6_... & 100 & 0.29 & PK5 & 5 Year Peak Flood & 32.1 \\
\hline 18 & 3 & gc1534 & 2012_5113_Region_6_... & 100 & 0.21 & PK5 & 5 Year Peak Flood & 27.2 \\
\hline 26 & 4 & gc1534 & 2012_5113_Region_6_... & 100 & 0.12 & PK5 & 5 Year Peak Flood & 20.5 \\
\hline 34 & 5 & gc1534 & 2012_5113_Region_6_... & 100 & 0.07 & PK5 & 5 Year Peak Flood & 15.6 \\
\hline 42 & 6 & gc1534 & 2012_5113_Region_6_.. & 100 & 0.12 & PK5 & 5 Year Peak Flood & 20.5 \\
\hline 50 & 7 & gc1534 & 2012_5113_Region_6_... & 100 & 0.12 & PK5 & 5 Year Peak Flood & 20.5 \\
\hline 58 & 8 & gc1534 & 2012_5113_Region_6_... & 100 & 0.0 & PK5 & 5 Year Peak Flood & 0.0 \\
\hline 66 & 9 & gc1534 & 2012_5113_Region_6_... & 100 & 0.0 & PK5 & 5 Year Peak Flood & 0.0 \\
\hline 74 & 10 & gc1534 & 2012_5113_Region_6_... & 100 & 0.95 & PK5 & 5 Year Peak Flood & 58.5 \\
\hline 82 & 11 & gc1534 & 2012_5113_Region_6_... & 100 & 0.95 & PK5 & 5 Year Peak Flood & 58.5 \\
\hline 90 & 12 & gc1534 & 2012_5113_Region_6_... & 100 & 0.0 & PK5 & 5 Year Peak Flood & 0.0 \\
\hline 98 & 13 & gc1534 & 2012_5113_Region_6_... & 100 & 0.0 & PK5 & 5 Year Peak Flood & 0.0 \\
\hline 106 & 14 & gc1534 & 2012_5113_Region_6_... & 100 & 0.43 & PK5 & 5 Year Peak Flood & 39.1 \\
\hline 114 & 15 & gc1534 & 2012_5113_Region_6_.. & 100 & 0.43 & PK5 & 5 Year Peak Flood & 39.1 \\
\hline 122 & 16 & gc1534 & 2012_5113_Region_6_... & 100 & 0.18 & PK5 & 5 Year Peak Flood & 25.2 \\
\hline 130 & 17 & gc1534 & 2012_5113_Region_6_... & 100 & 0.18 & PK5 & 5 Year Peak Flood & 25.2 \\
\hline 138 & 18 & gc1534 & 2012_5113_Region_6_... & 100 & 0.37 & PK5 & 5 Year Peak Flood & 36.3 \\
\hline 146 & 19 & gc1534 & 2012_5113_Region_6_... & 100 & 0.37 & PK5 & 5 Year Peak Flood & 36.3 \\
\hline 154 & 20 & gc1534 & 2012_5113_Region_6_... & 100 & 0.04 & PK5 & 5 Year Peak Flood & 11.8 \\
\hline 162 & 21 & gc1534 & 2012_5113_Region_6_... & 100 & 0.04 & PK5 & 5 Year Peak Flood & 11.8 \\
\hline 170 & 22 & gc1534 & 2012_5113_Region_6_... & 100 & 0.18 & PK5 & 5 Year Peak Flood & 25.2 \\
\hline 178 & 23 & gc1534 & 2012_5113_Region_6_... & 100 & 0.18 & PK5 & 5 Year Peak Flood & 25.2 \\
\hline
\end{tabular}

